NATIONAL AERONAUTICS AND SPACE ADMINISTRATION

Technical Report 32-1555

\title{
Neutron Radiation Characteristics of Plutonium Dioxide Fuel
}

\author{
Mojtaba Taherzadeh
}
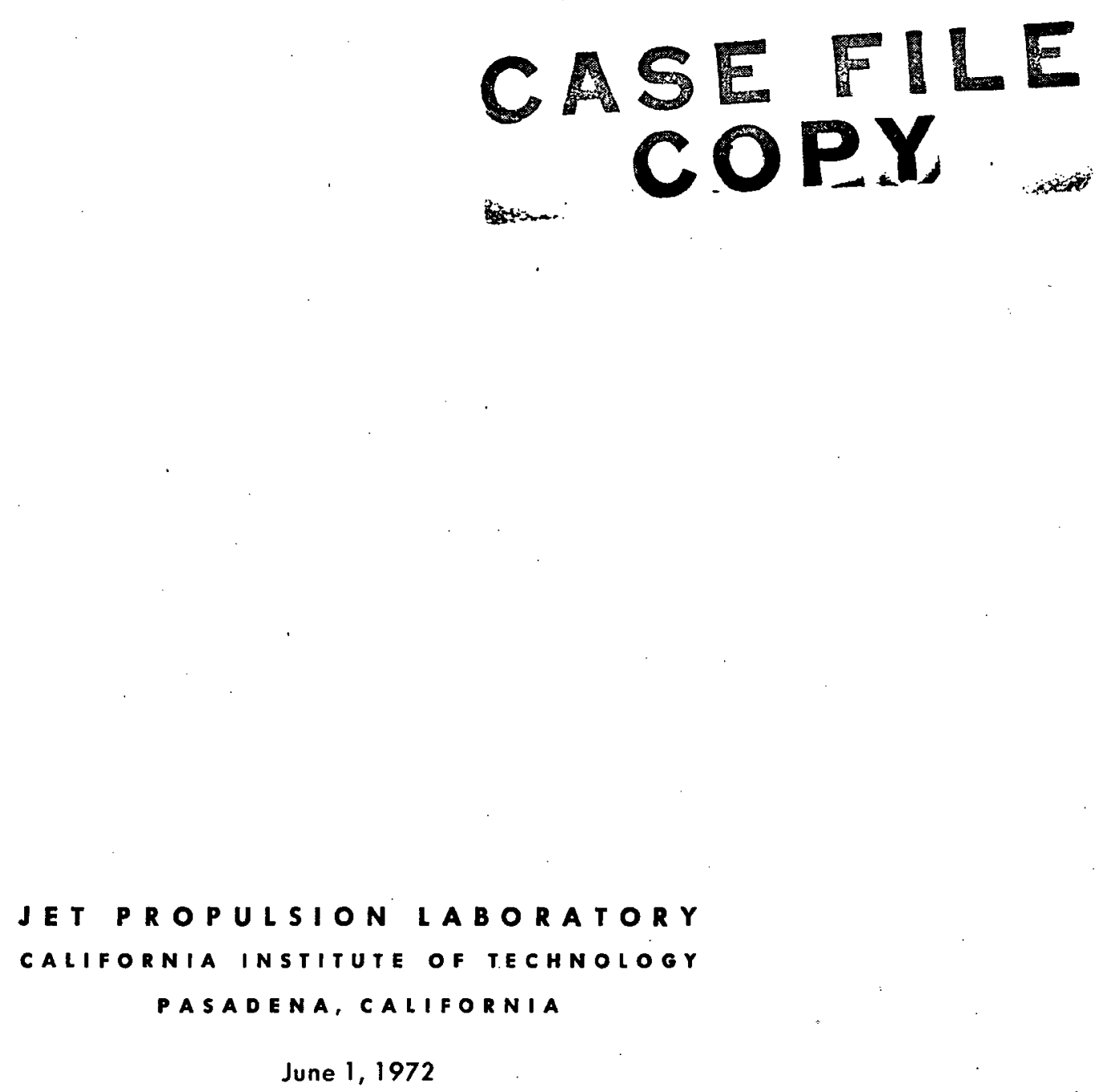
Technical Report 32-1555

\title{
Neutron Radiation Characteristics of Plutonium Dioxide Fuel
}

\author{
Mojtaba Taherzadeh
}

JET PROPULSION LABORATORY

CALIFORNIA INSTITUTE OF TECHNOLOGY

PASADENA, CALIFORNIA

June 1, 1972 


\section{Preface}

The work described in this report was performed by the Guidance and Control Division of the Jet Propulsion Laboratory. 


\section{Acknowledgment}

The author expresses appreciation to Dr. Melvin Reier for valuable discussions during this investigation, to Dr. Peter Gingo for contributions to the initial effort, to Dr. Vincent C. Truscello for continued interest and support, and to Mr. Michael A. Dore for setting up a computer code for one phase of this work. 


\section{Contents}

I. Introduction . . . . . . . . . . . . . . . . . . . . . 1

Ii. Spontaneous Neutron Radiation from ${ }^{238}$ Pu Isotopes . . . . . . . . . 1

A. Spontaneous Neutron Spectra of ${ }^{238} \mathrm{Pu}$. . . . . . . . . . . . . . . 2

B. Spontaneous Fission Parameters of Other Fuel Components . . . . . . . . 3

C. Combined Spontaneous Neutron Source Spectrum . . . . . . . . . . . 3

III. Analytical Calculation of the Neutron Yield from $(\alpha, n)$ Reactions

with Low-Z Impurities. . . . . . . . .. . . . . . . . . . . . . 4

A. Impurity Characteristics . . . . . . . . . . . . . . . . . . . . . 4

B. $(\alpha, n)$ Neutron Yield . . . . . . . . . . . . . . . . . . . . . 6

C. Total Neutron Yield . . . . . . . . . . . . . . . . . . . . 7

IV. Neutron Yield from $(\alpha, n)$ Reactions with ${ }^{18} \mathrm{O}$ Isotope . . . . . . . . . . . 8

V. The Overall Neutron Yield and Flux from $\mathrm{PuO}_{2}$ Fuel . . . . . . . . . 10

A. Total Neutron Source . . . . . . . . . . . . . . . . . . . 10

B. Neutron Flux from a MHW Fuel Capsule . . . . . . . . . . . . . . 12

C. Results and Conclusion . . . . . . . . . . . . . . . . . 13

References ...................... 15

\section{Tables}

1. Spontaneous fission parameters for plutonium isotopes . . . . . . . . . 3

2. Plutonium spontaneous neutron fission yield . . . . . . . . . . . . . 4

3. Alpha-emission characteristics of ${ }^{238 \mathrm{Pu}} \vec{a}^{234} \mathrm{U}^{*} \vec{\gamma}^{234} \mathrm{U}$ decay scheme . . . . 4

4. Characteristics of Pu isotopes as $\alpha$-emitters . . . . . . . . . . . . . 5

5. $(\alpha, n)$ reaction with impurities . . . . . . . . . . . . . . . . . . 5

6. Observed neutron yield for low-Z impurities . . . . . . . . . . . . . 6

7. Neutron yield due to $(\alpha, n)$ reactions with impurities in a ${ }^{238 P u}$ heat source . . . 7

8. Excited states of the recoil isotope in ${ }^{18} \mathrm{O}(\alpha, n)^{21} \mathrm{Ne}$ reaction . . . . . . . . . 8

9. Neutron yield comparison in the ${ }^{18} \mathrm{O}(\alpha, n)^{21} \mathrm{Ne}$ reaction . . . . . . . . . 10

10. Neutron yield from a $\mathrm{PuO}_{2}$ fuel power source ... . . . . . . . . . : 11

11. Fractions of low-Z impurities in a 2.2-kW (thermal) $\mathrm{PuO}_{2}$ fuel power source . . . 11

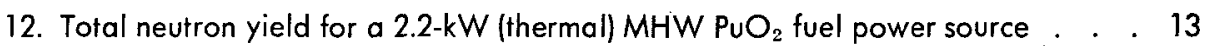

13. Neutron flux at nine detector points . . . . . . . . . . . . . . . 13 


\section{Contents (contd)}

\section{Figures}

1. Neutron spontaneous fission spectrum $\left(\mathrm{n} / \mathrm{s} / \mathrm{MeV} / \mathrm{g}^{238 \mathrm{Pu}}\right)$. . . . . . . . . 2

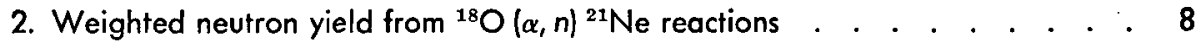

3. Neutron yield from the SRL experiment . . . . . . . . . . . . . . . 9

4. Monte Carlo result calculated for the SRL geometry with JPL neutron yield spectrum . . . . . . . . . . . . . . . . . . . . . . . 9

5. Total neutron yield from a 2.2-kW-MHW $\mathrm{PuO}_{2}$ source. . . . . . . . . . 11

6. The geometry setup of the 2.2-kW-MHW $\mathrm{PuO}_{2}$ fuel capsule . . . . . . . . 12

7. Neutron flux spectrum at 50-cm away from the 2.2-kW $\mathrm{PuO}_{2}$ fuel capsule . . . 14 


\begin{abstract}
The major sources of neutrons from plutonium dioxide nuclear fuel are considered in detail. These sources include spontaneous fission of several of the $\mathrm{Pu}$ isotopes, $(\alpha, n)$ reactions with low $Z$ impurities in the fuel, and $(\alpha, n)$ reactions with ${ }^{18} \mathrm{O}$. For spontaneous fission neutrons a value of $(1.95 \pm 0.07) \times 10^{3} \mathrm{n} / \mathrm{s} / \mathrm{g} \mathrm{PuO}$ is obtained.

The neutron yield from $(\alpha, n)$ reactions with oxygen is calculated by integrating the reaction rate equation over all $\alpha$-particle energies and all center-of-mass angles. The results indicate a neutron emission rate of $(1: 14 \pm 0.26) \times 10^{4} \mathrm{n} / \mathrm{s} / \mathrm{g} \mathrm{PuO}_{2}$.

The neutron yield from $(\alpha, n)$ reactions with low $Z$ impurities in the fuel is presented in tabular form for one part per million of each impurity. The total neutron yield due to the combined effects of all the impurities depends upon the fractional weight concentration of each impurity. The total neutron flux emitted from a particular fuel geometry is estimated by adding the neutron yield due to the induced fission to the other neutron sources.
\end{abstract}




\section{Neutron Radiation Characteristics of Plutonium Dioxide Fuel}

\section{Introduction}

One method of providing electrical power to spacecraft for outer planet missions is to utilize the heat produced in the radioactive $\alpha$-decay of ${ }^{238} \mathrm{Pu}$ in a $\mathrm{PuO}_{2}$-fueled radioisotope thermoelectric generator (RTG). Significant amounts of radiation are also given off by the fuel, including neutrons, $\gamma$-rays, and gamma radiation accompanying the $\alpha$-decays. This paper is concerned with accurately characterizing the neutron radiation in particular.

In order to obtain the neutron yield from $\mathrm{PuO}_{2}$ fuel, it is necessary to determine the number of neutrons resulting from each of the two major sources, spontaneous fission of the plutonium isotopes, which produce a "natural" neutron background, and $(\alpha, n)$ reactions with light elements present in the fuel. These light elements include oxygen as well as trace quantities of numerous other impurities contained in actual fuels. All of these neutrons are capable of causing induced fissioning in the plutonium, giving rise to still another source of neutrons. A fourth source of neutrons is from $(\gamma, n)$ reactions, although, as will be shown, this source is not significant. The neutron-producing reactions can therefore be summarized as (1) spontaneous fission, (2) induced fission, (3) $(\alpha, n)$ reactions with low $\mathbf{Z}$ isotopes, and (4) photoneutron formation.

In order to obtain the spectral distribution of the neutron radiation from a $\mathrm{PuO}_{2}$ heat source, the effects of all the above reactions must be combined. In this report each of these neutron spectra will be investigated individually and then combined to yield the composite spectrum. To simplify the calculation of these neutron spectra, any of a number of schemes may be adopted to eliminate one or more of the sources. For example, because of large surface-to-volume ratio, induced fission effects may be eliminated by choosing a disk-like source of $\mathrm{PuO}_{2}$. Moreover, by utilizing a plutonium metal source, such as the HP-15-2 source used in various phases of artificial heart research, only spontaneous fission neutrons will be of concern.

\section{Spontaneous Neutron Radiation from ${ }^{238} \mathrm{Pu}$ Isotopes}

The maximum binding energy per nucleon occurs at an atomic number of about 60 . In heavier nuclei the total binding energy can be increased by dividing the original nucleus into two smaller nuclei. These spontaneous fission reactions do not occur in the common elements because they are opposed by a potential barrier. In heavy elements such as ${ }^{238} \mathrm{Pu}$, the dissociation energy is above the barrier height, and spontaneous fission, in which neutrons are emitted, can take place. A plot of partial half-life for sponstaneous fission against the fission parameter $Z^{2} / A$ indicates that odd- $A$ nuclei have a much longer half-life for spontaneous fission than do even- $A$ nuclei with the 
same fission parameter. In the case of ${ }^{238} \mathrm{Pu}$ and ${ }^{239} \mathrm{Pu}$, the half-lives for spontaneous fission are about $5 \times 10^{10}$ and $10^{16}$ years, respectively. ${ }^{1}$

These fissionable elements, however, are also $\alpha$-emitters with much shorter half-lives (i.e., 86.4 years for ${ }^{238} \mathrm{Pu}$ and $2.4 \times 10^{4}$ years for ${ }^{239} \mathrm{Pu}$ ). Thus one expects the spontaneous radiation to be less important than $(\alpha, n)$ reactions. Nevertheless, one cannot ignore the fact that these spontaneous fission neutrons are capable of induced fission and can have energies as much as $10 \mathrm{MeV}$ or higher. This means they can cause considerable damage to scientific packages if they are exposed for long periods of time.

\section{A. Spontaneous Neutron Spectra of ${ }^{238 P u}$}

Since plutonium metal used as a heat source and furnished by AEC does not emit pure spontaneous fission neutrons, the mixed radiation of the plutonium heat source must be analyzed. Clearly, it is possible to obtain the neutron fission spectrum of a plutonium power source by fitting a Maxwellian distribution to the experimental data and thereby obtaining the required parameters to simulate the neutron spectrum (Ref. 1). However, since a pure plutonium source is difficult to make because of the lack of techniques for removal of impurities, the contribution from a mixture of impurities and different plutonium isotopes will cause the fitted parameter to be incorrect or biased. Thus a scheme which allows the least bias of impurities and mixture of isotopes has to be used.

Anderson and Neff (Ref. 2) of Monsanto Research Corporation used a HP15-2 metal radiation power source to obtain the pure spontaneous fission neutrons. The neutron spectrum of this source was composed of neutrons from both spontaneous fission of ${ }^{238} \mathrm{Pu}$ and from $(\alpha, n)$ reactions with impurities in the fuel. The researchers estimated that 75\% of these neutrons were from spontaneous fission and that these made up essentially all of the spectrum for energies greater than $5 \mathrm{MeV}$. Thus by using this argument and data points from 5 to $14 \mathrm{MeV}$, they used a weighted least-square fit to a Maxwellian distribution in order to approximate the spontaneous fission spectrum. The result of this fit is found to be:

$$
N(E)=2.04 \times 10^{3}(E)^{1 / 2} \exp (-E / 1.34)
$$

in $\mathrm{n} / \mathrm{s} / \mathrm{MeV} / \mathrm{g}^{238} \mathrm{Pu}$, where $E$ is the energy of the emitted neutrons in $\mathrm{MeV}$.

\footnotetext{
${ }^{1} \mathrm{~A}$ more accurate value of spontaneous fission half life of ${ }^{238} \mathrm{Pu}$ has been obtained by Los Alamos and Argonne Laboratories.
}

Integration of this equation over all energies gives the total neutron yield from ${ }^{238} \mathrm{Pu}$ spontaneous fission. A fraction of the neutrons with energy greater than $5 \mathrm{meV}$ is due to the induced fission neutrons, but the shape of the spectrum of these neutrons is the same as for the spontaneous neutrons (Fig. 1).

Using Eq. (1), the average neutron yield may be evaluated; that is,

$$
y=\int_{0}^{\infty} N(E) d E=2.8 \times 10^{3}
$$

in $\mathrm{n} / \mathrm{s} / \mathrm{g}{ }^{238} \mathrm{Pu}$.

Since the maximum energy of neutrons from ${ }^{18} \mathrm{O}(\alpha, n)$ is about $4.5 \mathrm{meV}$ and only $12 \%$ of the neutrons were estimated to be due to $(\alpha, n)$ reactions with impurities, ${ }^{2}$ the ${ }^{2}$ From a nonrelativistic two-body reaction and by using $5.5-\mathrm{MeV}_{\alpha}$
particle energy (Ref. 3).

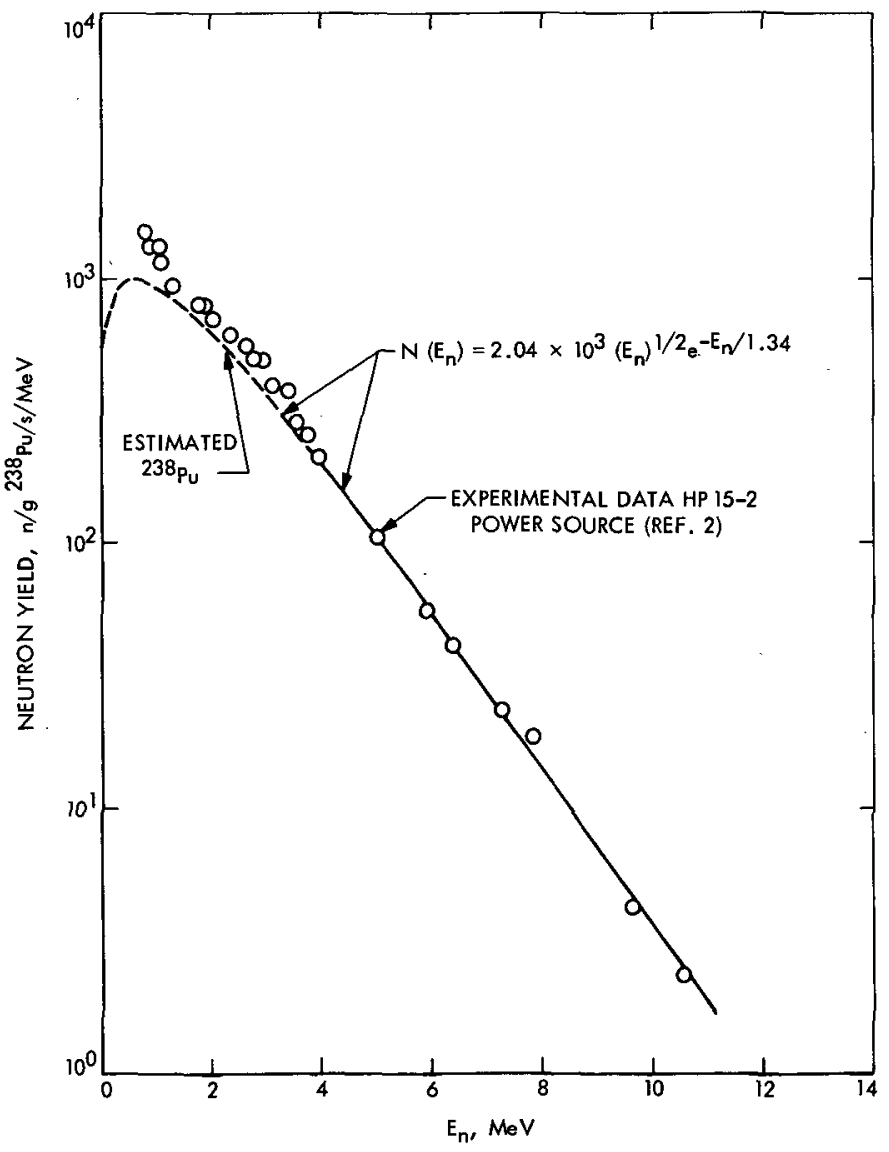

Fig. 1. Neutron spontaneous fission spectrum (n/s/MeV/g $\left.{ }^{238 P u}\right)$ 
assumption that beyond $5 \mathrm{MeV}$ nearly all the neutrons are from spontaneous emission was justified and, therefore Eq. (1) may be used as the spontaneous fission spectrum equation.

A Maxwellian distribution is assumed here because the neutrons emitted from the nucleus are modeled to a Fermi gas of temperature $T$, and therefore the normalized energy distribution is given by $\eta_{N}(E)$ :

$$
\eta_{N}(E)=2 \pi^{-1 / 2} T^{-3 / 2} E^{1 / 2} \exp (-E / T)
$$

where $T$ is the corresponding nuclear gas temperature.

This equation depends only on the one parameter $T$ which, on comparison with Eq. (1), would be equal to $1.34 \mathrm{MeV}$ for spontaneous emission of neutrons from ${ }^{238} \mathrm{Pu}$. The upper limit of the errors on this parameter from all sources had been estimated (Ref. 2) to be about 5\%. Utilizing this error, the theory and experiment set a value of $(1.34 \pm 0.07) \mathrm{Mev}$ for the nuclear temperature of ${ }^{238} \mathrm{Pu}$.

The average energy is calculated by using the normalized energy spectrum and is equal to $(2.0 \pm 0.1) \mathrm{MeV}$; the most probable neutron energy corresponds to the peak value of the neutron energy distribution, $E_{p}=T / 2=$ $(0.67 \pm 0.03) \mathrm{MeV}$.

\section{B. Spontaneous Fission Parameters of Other Fuel Components}

So far, the spontaneous fission parameters of neutrons from ${ }^{238} \mathrm{Pu}$ have been calculated. By having the Maxwellian distribution one is able to obtain neutron yield and average energy, or by using the average number of neutrons per fission one is able to calculate the energy spectrum, if the fission parameter is known.
Since a pure ${ }^{238} \mathrm{Pu}$ isotope in a fuel furnished by AEC as a heat source does not exist, the contribution from other plutonium isotopes mixed up with the ${ }^{238} \mathrm{Pu}$ should be considered. If a similar nuclear emission model is assumed for each of the isotopes, one needs only two parameters to estimate their emission rates or energy spectra: the fission parameter $v$ and the neutron yield $Y$. Table 1 summarizes these parameters for the spontaneous fission of $\mathrm{Pu}$ isotopes; Table 2 presents the spontaneous fission yield of all the plutonium isotopes in the fuel.

\section{Combined Spontaneous Neutron Source Spectrum}

In order to obtain the combined spontaneous neutron emission from a nuclear fuel consisting of a number of isotopes, the radiation spectra of all components should be combined according to their fractional weight and halflife ratio. Weightwise, the only other component isotope which may contribute a significant amount of radiation is ${ }^{239} \mathrm{Pu}$, but the ratio of half-life of ${ }^{239} \mathrm{Pu} /{ }^{238} \mathrm{Pu}$ is equal to about $10^{-5}$. Therefore, it is clear that only ${ }^{238} \mathrm{Pu}$ need be used to obtain spontaneous neutron spectrum and yield. This is emphasized by the fact that the total contribution of neutrons from spontaneous emission is only a fraction of the total neutron yield.

In Table 1, various values of fission parameters such as number of neutrons/fission $v$, average energy of emerging neutrons $E$, the most probable energy $E_{p}$, half-life $T_{3 / 2}$, and the corresponding values of nuclear temperature are quoted for different plutonium isotopes included in the power source. Even though these values are within $10 \%$ of their average values, the radiation spectrum of each isotope is calculated separately because of tremendous differences in their half-lives and percent weight contribution to the overall weight of the fuel. For ${ }^{238} \mathrm{Pu}$ isotope, $v=(2.33 \pm 0.08)$ neutron/fission, $f=1.165 \times 10^{3}$ fission/ $\mathrm{g} / \mathrm{s}$, the neutron yield $y=(2.71 \pm 0.09) \times 10^{3} \mathrm{n} / \mathrm{g}{ }^{238} \mathrm{Pu} / \mathrm{s}$,

Table 1. Spontaneous fission parameters for plutonium isotopes (Furnished by AEC as a heat source)

\begin{tabular}{|c|c|c|c|c|c|c|}
\hline Pu isotopes & Abundance,$\%$ & $\nu(n / f)^{\prime \prime}$ & $\mathrm{E}, \mathrm{MeV}$ & $E_{p}, \mathrm{MeV}$ & $T, \mathrm{MeV}$ & Power, W/g \\
\hline 236 & $1.2 \times 10^{-4}$ & $2.30 \pm 0.19$ & 1.96 & 0.655 & 1.31 & 18 \\
\hline 238 & 80.27 & $2.33 \pm 0.08$ & 1.965 & 0.66 & 1.34 & 0.55 \\
\hline 239 & 15.87 & $2.88 \pm 0.016$ & 2.065 & 0.69 & 1.38 & $1.9 \times 10^{-3}$ \\
\hline 240 & 3.022 & $2.257 \pm 0.046$ & 1.955 & 0.655 & 1.31 & $6.9 \times 10^{-9}$ \\
\hline 242 & 0.643 & $3.03 \pm 0.03$ & 2.08 & 0.695 & 1.38 & $4.7 \times 10^{-3}$ \\
\hline 242 & 0.132 & $2.18 \pm 0.09$ & 1.946 & 0.65 & 1.30 & $1.2 \times 10^{-6}$ \\
\hline
\end{tabular}

"Obtained from Ref. 4.

bobtained from Ref. 5. 
Table 2. Plutonium spontaneous neutron fission yield

\begin{tabular}{|c|c|c|c|c|c|c|}
\hline \multirow{2}{*}{ Pu isotopes (i) } & \multirow[b]{2}{*}{ Abundance, $\%$} & \multirow[b]{2}{*}{$T_{1 / 2, y r}$} & \multirow{2}{*}{$\begin{array}{c}(1) \\
f_{238} T_{1 / 2} / T_{1 / 2}^{i}\end{array}$} & \multicolumn{3}{|c|}{ Neutron yield } \\
\hline & & & & $\underset{\mathrm{n} / \mathrm{gPu}^{1} / \mathrm{s}}{(2)}$ & $\underset{n / g ~ P u^{1} / s}{(3)}$ & $\begin{array}{c}\text { (4) } \\
\mathrm{n} / \mathrm{g} \mathrm{PuO}_{2} / \mathrm{s}\end{array}$ \\
\hline 236 & $1.2 \times 10^{-4}$ & $3.5 \times 10^{\circ}$ & $1.43 \times 10^{3}$ & $3.3 \times 10^{4}$ & $3.93 \times 10^{-2}$ & $3.46 \times 10^{-2}$ \\
\hline 238 & 80.27 & $4.3 \times 10^{10}$ & $1.16 \times 10^{3}$ & $2.71 \times 10^{3}$ & $2.18 \times 10^{8}$ & $1.92 \times 10^{3}$ \\
\hline 239 & 15.87 & $5.5 \times 10^{15}$ & $9.1 \times 10^{-8}$ & $2.63 \times 10^{-2}$ & $4.19 \times 10^{-3}$ & $3.60 \times 10^{-3}$ \\
\hline 240 & 3.02 & $1.22 \times 10^{11}$ & $4.1 \times 10^{2}$ & $9.27 \times 10^{2}$ & $2.80 \times 10^{1}$ & $2.46 \times 10^{1}$ \\
\hline 241 & 0.643 & $\begin{array}{l}5.0 \times 10^{15} \\
\text { (estimated) }\end{array}$ & $1.0 \times 10^{-2}$ & $3.04 \times 10^{-2}$ & $1.95 \times 10^{-4}$ & $1.77 \times 10^{-4}$ \\
\hline 242 & 0.143 & $6.8 \times 10^{10}$ & $7.87 \times 10^{2}$ & $1.61 \times 10^{3}$ & $2.3 \times 10^{0}$ & $2.02 \times 10^{0}$ \\
\hline$\because$ & & & & Total & $2.21 \times 10^{3}$ & $1.95 \times 10^{2}$ \\
\hline
\end{tabular}

(1): the number of fissions/g Put/s.

(2): the neutron yield for $\mathrm{Pu}^{4}$.

(3): the neutron yield for $\mathrm{Pu}^{i}$ in the fuel, Table 1.

(4): the neutron yield for each plutonium isolope dioxide in the fuel.

and for a 2200-W (thermal) metal fuel, disk-shaped power source, $M=3.52 \times 10^{3} \mathrm{~g}$, the total neutron rate would be $(9.60 \pm 0.34) ; \times 10^{6}$ neutron/s. Multiplying the neutron yield by the fraction of ${ }^{238} \mathrm{Pu}$ in $\mathrm{Pu}$, namely 0.81 , a total of $2.2 \times 10^{3} \mathrm{n} / \mathrm{g} \mathrm{Pu} / \mathrm{s}$ is obtained. Moreover, if the neutron yield for the spontaneous fission per gram $\mathrm{Pu}$ per second is multiplied by the fraction of $\mathrm{Pu}$ in $\mathrm{PuO}_{2},(0.8814)$, the neutron yield from spontaneous fission will be equal to $1.95 \times 10^{3} \mathrm{n} / \mathrm{g} \mathrm{PuO}_{2} / \mathrm{s}$.

\section{Analytical Calculation of the Neutron Yield from $(\alpha, n)$ Reactions with Low-Z Impurities}

Impurities are usually found in a plutonium heat source because of the lack of techniques to remove them completely. Clearly, $(\alpha, n)$ reactions can take place with all impurity elements in the fuel when the energy of the incoming $\alpha$ particle is greater than the threshold energy of the reaction. However, both the height of the potential barrier of the target nucleus and the $\alpha$-ray. energy should be within an allowable range. Therefore, it may be assumed that the neutron yield from high- $Z$ impurities is small, and the element with atomic number equal to 14 (i.e., silicon) is the highest element for which the neutron yield need be calculated (Ref. 6).

\section{A. Impurity Characteristics}

The $\alpha$ particle emitted from the plutonium isotope has various energies with different probabilities of emission. The energy and the emission rate of the $\alpha$ particle from the ${ }^{238} \mathrm{Pu}$ decay process depend upon the excited states of the daughter nucleus, namely, ${ }^{234} \mathrm{U}$ isotope. The ${ }^{238} \mathrm{Pu}$ isotope decays into the ground state of ${ }^{234} \mathrm{U}$ isotope $71 \%$ of the time; the corresponding $\alpha$ particle has an energy of $5.491 \mathrm{MeV}$ (Refs. 7-9). If the daughter nucleus is left in the first excited state, the $\alpha$-particle energy will be $5.448 \mathrm{MeV}$, with an emission rate of $29 \%$. Table 3 summarizes these values for the ${ }^{238} \mathrm{Pu}$ to ${ }^{234} \mathrm{U}$ decay scheme. The emission rates from other excited states of ${ }^{234} \mathrm{U}$ are negligible, and thus an average energy of $5.48 \mathrm{MeV}$ can be used for the $\alpha$-particle energy emitted from ${ }^{238} \mathrm{Pu}$. An $\alpha$ particle, when passing through an impurity element or plutonium isotopes; loses energy by ionization and excitation processes. This means the energy loss of $\alpha$ particles plays an important part in the neutron yield determination.

The $\gamma$-ray energy emitted from the excited states of the daughter nucleus $\left({ }^{234} U^{*}\right)$ has a maximum energy of

Table 3. Alpha-emission characteristics of ${ }^{238 P u} \underset{\alpha}{\rightarrow}{ }^{234} U^{*} \rightarrow{ }^{234} U$ decay scheme

(Ref. 8)

\begin{tabular}{ccccccc}
\hline $\begin{array}{c}\text { Excited } \\
\text { state of } \\
234 \mathrm{U}\end{array}$ & $\begin{array}{c}\text { Ground } \\
\text { state }\end{array}$ & $\begin{array}{c}\text { First } \\
\text { excited } \\
\text { state }\end{array}$ & $\begin{array}{c}\text { Second } \\
\text { excited } \\
\text { state }\end{array}$ & $\begin{array}{c}\text { Third } \\
\text { excifed } \\
\text { stafe }\end{array}$ & $\begin{array}{c}\text { Fourth } \\
\text { excited } \\
\text { state }\end{array}$ & $\begin{array}{c}\text { Fifth } \\
\text { excited } \\
\text { state }\end{array}$ \\
\hline $\begin{array}{c}\alpha \\
\text { emission, } \\
\%\end{array}$ & 71 & 29 & 0.13 & 0.005 & $7 \times 10^{-6}$ & $10^{-4}$ \\
$\begin{array}{c}E_{\text {ar, }} \\
\mathrm{MeV}\end{array}$ & 5.491 & 5.448 & 5.35 & 5.2 & 5.0 & - \\
$\begin{array}{c}\mathrm{E}_{*}^{*} \\
\mathrm{MeV}\end{array}$ & 0 & 0.0435 & 0.293 & 0.43 & 0.499 & 0.81 \\
\hline
\end{tabular}


$43.5 \mathrm{keV}$ and thus will be absorbed by the source or the shield surrounding it. Photons are also radiated from different plutonium isotopes in the fuel and from the $(\alpha, n)$ reactions; these are not the subject of this study.

Table 4 summarizes different parameters in the $\alpha$-decay process (Ref. 10) of all the important plutonium isotopes considered. The energy of the $\alpha$ particle was averaged over the probabilities of $\alpha$ emission, and $F_{\alpha}$ is calculated to indicate the effect of other isotopes besides ${ }^{238} \mathrm{Pu}$ on the neutron spectrum in general. The $F_{a}$ has been evaluated by multiplying the ratio of half-lives by the percent weight of each plutonium isotope. From the values of the last column, it can be concluded that the contributions to the total number of $(\alpha, n)$ reactions are mainly due to the ${ }^{238} \mathrm{Pu}$ isotope.

Table 5 summarizes the list of low- $Z$ impurities which have an acceptable threshold energy for $(\alpha, n)$ reactions. The potential barrier height $B$ is equal to

$$
Z z e^{2}\left(r_{0} A^{1 / 3}+1.2\right)^{-1}
$$

where $e^{2}=1.44 \mathrm{MeV}$-Fermi, $r_{0}=1.3 \mathrm{Fermi}, Z$ and $z$ are the target and $\alpha$-particle atomic number, respectively, and $r_{0}$ is the nuclear radius. In the classical sense, the $(\alpha, n)$

Table 4. Characteristics of Pu isotopes as $\alpha$-emitfers

\begin{tabular}{|c|c|c|c|c|c|c|c|}
\hline Pu isotopes & Weight percent & $\alpha$-activity, $\alpha / g / s$ & $T_{1 / 2(\alpha), y r}$ & $\begin{array}{c}\alpha, \beta, \text { or } \gamma \\
\text { emission }\end{array}$ & $\begin{array}{c}\text { E weighted, } \\
\mathrm{MeV}\end{array}$ & $T_{1 / 4}$ ratio & $\boldsymbol{F}_{\alpha}$ \\
\hline 236 & $1.2 \times 10^{-4}$ & $1.96 \times 10^{13}$ & 2.85 & $\alpha$ & 5.73 & 33 & $4.0 \times 10^{-5}$ \\
\hline 238 & 80.27 & $6.4 \times 10^{11}$ & $\begin{array}{c}86.4 \\
(89.6)\end{array}$ & $\alpha, \gamma$ & 5.51 & 1.0 & $8.027 \times 10^{-1}$ \\
\hline 239 & 15.87 & $2.28 \times 10^{9}$ & $2.44 \times 10^{4}$ & $\alpha, \gamma$ & 5.51 & $3.6 \times 10^{-3}$ & $5.70 \times 10^{-11}$ \\
\hline 240 & 3.022 & $8.43 \times 10^{\circ}$ & $6.58 \times 10^{8}$ & $\alpha$ & 5.18 & $1.32 \times 10^{-2}$ & $3.96 \times 10^{-4}$ \\
\hline 241 & 0.643 & $1.7 \times 10^{8}$ & 13.2 & $\begin{array}{l}0.0024 \alpha \\
\beta(99 \%)\end{array}$ & 4.893 & 6.54 & $4.20 \times 10^{-1}$ \\
\hline 242 & 0.132 & $1.47 \times 10^{8}$ & $3.79 \times 10^{5}$ & $\begin{array}{l}\gamma \\
\alpha\end{array}$ & 4.87 & $2.79 \times 10^{-4}$ & $3.68 \times 10^{-1}$ \\
\hline
\end{tabular}

Table 5. $(\alpha, n)$ reaction with impurities ${ }^{a}$

\begin{tabular}{|c|c|c|c|c|c|c|c|c|c|}
\hline Impurity & $\mathbf{z}$ & A & $\begin{array}{c}(m-A) \\
\times \quad 10^{3}, \mathrm{cmu}\end{array}$ & $\begin{array}{l}\left(E_{n}\right)_{\text {th }} \\
M e V\end{array}$ & $\begin{array}{c}\left(E_{n}\right)_{\text {max, }} \\
\text { MeV }\end{array}$ & $\begin{array}{c}\text { Q, } \\
\text { MeV }\end{array}$ & $\begin{array}{l}\text { B, } \\
\text { MeV }\end{array}$ & $\begin{array}{c}\text { Abundance, \% } \\
\text { (Ref. 11) }\end{array}$ & Reaction \\
\hline \multirow[t]{2}{*}{ Li } & 3 & 7 & 18.223 & 4.39 & 3.57 & -2.79 & 2.33 & 92.1 & $\mathrm{Li}^{\mathrm{T}}(\alpha, n) \mathrm{B}^{10}$ \\
\hline & 3 & 8 & 25.018 & - & 13.54 & 6.63 & 2.27 & $\sim 0.0$ & $L_{i}^{8}(\alpha, n) B^{11}$ \\
\hline \multirow[t]{2}{*}{$\mathrm{Be}$} & 4 & 9 & 15.043 & - & 12.47 & 5.71 & 2.95 & 100.0 & $B e^{2}(\alpha, n) C^{12}$ \\
\hline & 4 & 10 & 16.711 & - & 10.45 & 3.85 & 2.88 & $\sim 0.0$ & $\operatorname{Be}^{10}(\alpha, n) C^{13}$ \\
\hline \multirow[t]{3}{*}{ B } & 5 & 10 & 16.114 & - & 7.55 & 1.07 & 3.60 & 18.4 & $\mathrm{~B}^{10}(\alpha, n) \mathrm{N}^{13}$ \\
\hline & 5 & 11 & 12.789 & - & 6.51 & 0.15 & 3.52 & 81.6 & $B^{11}(\alpha, n) N^{14}$ \\
\hline & 5 & 12 & 18.162 & - & 14.17 & 7.36 & 3.45 & 0.0 & $\mathrm{~B}^{14}(\alpha, n) \mathrm{N}^{1 \mathrm{~s}}$ \\
\hline \multirow[t]{2}{*}{ C } & 6 & 13 & 7.473 & 一 & 8.54 & 2.20 & 4.06 & 1.1 & $C^{11}(\alpha, n) O^{18}$ \\
\hline & 6 & 14 & 7.515 & 2.55 & 4.07 & -1.98 & 3.99 & 0.0 & $C^{12}(\alpha, n) O^{17}$ \\
\hline \multirow[t]{2}{*}{0} & 8 & 17 & 4.533 & - & 6.71 & 0.60 & 5.07 & 0.04 & $\mathrm{O}^{17}(\alpha, n) \mathrm{Ne}^{20}$ \\
\hline & 8 & 18 & 4.857 & 0.86 & 5.31 & -0.70 & 5.00 & 0.204 & $\mathrm{O}^{18}(\alpha, n) \mathrm{Ne}^{21}$ \\
\hline \multirow[t]{3}{*}{$\mathbf{F}$} & 9 & 18 & 6.651 & 3.12 & 3.34 & -2.56 & 5.63 & 0.0 & $\mathrm{~F}^{18}(\alpha, n) \mathrm{Na}^{21}$ \\
\hline & 9 & 19 & 4.456 & 2.33 & 4.00 & -1.92 & 5.55 & 100.0 & $\mathbf{F}^{19}(\alpha, n) \mathrm{Na}^{22}$ \\
\hline & 9 & 20 & 6.350 & - & 10.14 & 3.90 & 5.48 & 0.0 & $\mathrm{~F}^{20}(\alpha, n) \mathrm{Na}^{28}$ \\
\hline $\mathrm{Na}$ & 11 & 23 & -2.945 & - & 9.16 & 3.15 & 6.40 & 100.0 & $\mathrm{Na}^{24}(\alpha, n) \mathrm{Al}^{27}$ \\
\hline \multirow[t]{3}{*}{ Mg } & 12 & 25 & -6.255 & - & 8.52 & 2.67 & 6.90 & 11.5 & $\mathrm{Mg}^{25}(\alpha, n) \mathrm{Si}^{28}$ \\
\hline & 12 & 26 & 9.190 & - & 5.93 & 3.99 & 6.84 & 11.1 & $\mathrm{Mg}^{26}(\alpha, n) \mathrm{Si}^{20}$ \\
\hline & 12 & 27 & -7.124 & - & 10.19 & 4.22 & 6.78 & 0.0 & $M g^{27}(\alpha, n) S^{20}$ \\
\hline Al & 13 & 28 & -9.230 & - & 7.88 & 1.96 & 7.27 & 100.0 & $\left.A\right|^{28}(\alpha, n) P^{\pi 1}$ \\
\hline \multirow[t]{3}{*}{ Si } & 14 & 29 & -14.340 & 1.80 & 4.22 & -1.58 & 7.76 & 6.2 & $S i^{29}(\alpha, n) S^{22}$ \\
\hline & 14 & 30 & -16.763 & 4.22 & 1.94 & -3.73 & 7.70 & 4.2 & $S i^{30}(\alpha, n) S^{23}$ \\
\hline & 14 & 31 & -14.850 & - & 7.05 & 1.18 & 7.63 & 0.0 & $S i^{31}(\alpha, n) S^{24}$ \\
\hline
\end{tabular}

Atomic mass numbers are obtained from Ref. 12. 
reaction is not allowed if $E_{\alpha}<B$ even though $E_{t h}<E_{\alpha}$; however, from quantum mechanics only the value of the transmission coefficient can determine the transparency of the Coulomb potential barrier (CPB). The transmission coefficient for the $S$ wave $\alpha$ particle is $T_{0}=e^{-\gamma}$, where $\gamma$ is the "Gamow" factor and is equal to

$$
\gamma=\pi\left(\frac{2 Z z}{137 \beta}\right)
$$

where $\beta=v_{\alpha} / C$. Since $\left(E_{\alpha}\right)_{\max }=5.5 \mathrm{MeV},\left(\beta_{\min }=0\right.$, $\left.\beta_{\max }=0.05\right)$ and $\left(\gamma_{\min }=+1.83 Z, \gamma_{\max }=\infty\right)$. This means the transmission coefficient has a range of

$$
T_{0}=[0, \exp (-1.83 Z)]
$$

For silicon, $T_{0}$ is $10^{-11}$ while for $\mathrm{Cd}$ it is $10^{-39}$; therefore, one can neglect the contribution from those impurities which have a very small probability of penetrating the potential barrier.

\section{B. $(\alpha n)$ Neutron Yield}

The neutron yield from impurities $y_{i}$ in a mixture can be written in terms of the experimentally measured neutron yield from target impurity atoms, the activity of the plutonium radioactive nuclei, and the straggling ratio; that is (Refs. $3,6,13$ ),

$$
Y_{i}=K(\lambda N)_{P u} y_{0_{i}}\left(\frac{S_{i} N_{i}}{\sum_{j} S_{j} N_{j}+S_{P u} N_{P u}}\right)
$$

where $K$ is the fraction of the $\alpha$-emitter, $(\lambda N)_{P u}$ is called the $\alpha$-activity of the emitter source, and $Y_{o_{i}}$ is the experimentally measured neutron yield for the impurity in question. The last fraction in the expression above accounts for the effect of competition between the $(\alpha, n)$ reactions and other unwanted ionization processes by which $\alpha$ particles also lose energy and is termed the straggling ratio. Therefore, the neutron source density depends upon the degree of mixing of the $\alpha$-particle source and impurities. The term $\lambda$ is the disintegration constant and is equal to $0.693 / T_{1 / 2} ; N$ is the total number of radioactive atoms of the emitter. The term $(\lambda N)$ is given in units of curies (one curie is equal to $3.7 \times 10^{10}$ disintegrations per second) and $\lambda N=-d N(t) / d t$, where $N(t) / N(0)=\exp (-\lambda t)$ is the number of radioactive atoms left at time $t$. The term $S_{i}$ is the $i$ th element atomic stopping power and is proportional (Ref. 6) to $Z_{i}\left(Z_{i}+7\right)^{-1 / 2}$.
Table 6 presents the experimental values of the $n / \alpha$ yield $\left(y_{0}\right)$ for different low- $Z$ materials, as reported by different groups. The results of Gorshkov (Ref. 14), owing to its detailed experimental study and small errors reported, are employed here. Equation (4) is used to evaluate neutron yields for all the impurities involved, and the yields are compared with other measured data.

\begin{tabular}{|c|c|c|c|c|c|}
\hline \multirow[b]{2}{*}{ Element } & \multirow[b]{2}{*}{$Z$} & \multirow[b]{2}{*}{$A$} & \multicolumn{3}{|c|}{ Neutron yield, $n / 10^{6} \alpha$} \\
\hline & & & Gorshkov (Ref. 14) & $\begin{array}{c}\text { Roberts } \\
\text { (Ref. I1) } \\
\text { (corrected) }\end{array}$ & $\begin{array}{c}\text { Breen, Hertz, } \\
\text { and Wright } \\
\text { (Ref. 15) }\end{array}$ \\
\hline Li & 3 & 7 & 一 & 2.6 & 1.0 \\
\hline $\mathrm{Be}$ & 4 & 9 & $84.4 \pm 0.9$ & 80 & 59 \\
\hline B & 5 & 10 & $19.6 \pm 0.2$ & 24 & 15 \\
\hline C & 6 & 12 & $0.113 \pm 0.015$ & 0.11 & - \\
\hline 0 & 8 & 16 & $0.068 \pm 0.011$ & 0.07 & - \\
\hline $\mathbf{F}$ & 9 & 19 & $11.6 \pm 0.2$ & 12 & - \\
\hline No & 11 & 23 & 一 & 1.5 & 1.1 \\
\hline \multirow[t]{2}{*}{$\mathrm{Mg}$} & 12 & 25 & $1.33 \pm 0.04$ & 1.4 & 0.80 \\
\hline & 13 & 27 & $0.16 \pm 0.03$ & 0.14 & 0.53 \\
\hline Si & 14 & 28 & $16.5 \pm 0.02$ & 16 & 一 \\
\hline $\mathrm{Cl}$ & $\cdot 17$ & 35 & - & 0.11 & - \\
\hline $\mathbf{A}$ & 18 & 36 & - & 0.38 & - \\
\hline $\mathbf{P}$ & 15 & 31 & - & - & 一 \\
\hline $\mathbf{s}$ & 16 & 32 & - & - & - \\
\hline
\end{tabular}

\section{Table 6. Observed neutron yield for low-Z impurities ${ }^{a}$ ( $E_{\alpha}=5.298 \mathrm{Mev}$ from Polonium)}

"A is the atomic mass number for the most abundant isotope in an element (Table 5), and yields are for a mixed isotope target.

In order to simplify Eq. (4), it may be assumed (Ref. 13) that $(\mathrm{SN})_{i}<<(\mathrm{SN})_{P u}$, and since Avogadro's number $N_{0}$ is equal to $(N A / \rho)$ (Ref. 3 )

$$
\begin{aligned}
y_{i} & =K \lambda_{P u} y_{0_{i}} \frac{S_{i}}{S_{P u}} \frac{m_{i} N_{0}}{A_{i}} \\
\frac{y_{i}}{m_{P u}} & =K \lambda_{P u} y_{0_{i}} \frac{S_{i}}{S_{P u}} \frac{m_{i}}{m_{P u}} \frac{N_{0}}{A_{i}} \\
Y_{i} \equiv \frac{\frac{y_{i}}{m_{P u}}}{\frac{m_{i}}{m_{P u}}} & =K \lambda_{P u} N_{0}\left(\frac{y_{0}}{A}\right)_{i}\left(\frac{S_{i}}{S_{P u}}\right)
\end{aligned}
$$

where $Y_{i}$ is the neutron yield of the $i$ th impurity per gram of plutonium per part impurity, and $y_{0_{i}}$ is the observed atomic neutron yield of the $i$ th impurity and is given in neutron yield/ $\alpha$-particle. Thus the total neutron yield of an impurity is given by Eq. (6) in neutrons/gram of plutonium/second/part of impurity. 


\section{Total Neutron Yield}

The observed number of neutrons per $\alpha$-particle in the $(\alpha, n)$ reaction with impurities has been reported by different groups. Table 6 shows the observed atomic neutron yield in $n / 10^{6} \alpha$ for impurities up to silicon.

Through the use of Eq. (6) and Tables 4 and 6, neutron yields of all impurities capable of producing neutrons can be obtained. By knowing the neutron yield of each impurity, the total neutron yield of the actual fuel (where the $\alpha$-emitter is mixed with other impurities) can be calculated. This is achieved simply by adding the contributions from all the impurities to obtain the total yield, namely,

$$
Y=\sum_{i} f_{i} Y_{i}=K \lambda_{P u} N_{0} \sum_{i}\left(\frac{y_{0}}{A}\right)_{i}\left(\frac{S_{i}}{S_{P u}}\right) f_{i}
$$

where $f_{i}$ is the fractional weight of the $i$ th impurity, $K \lambda_{P u}$ depends on the $\alpha$-emitter, $y_{0}$ is the measured number of neutrons $/ \alpha$, and $S_{i} / S_{P u}$ depends on the $Z$-number of each impurity. Since $S_{i}$ is proportional to $Z(Z+7)^{-1 / 2}$ [Matlack and Metz (Ref. 6)],

$$
Y=K \lambda_{P u} N_{0} \sum_{i}\left[\left(\frac{y_{0}}{A}\right)_{i}\left(\frac{Z_{i}}{Z_{P u}}\right)\left(\frac{7+Z_{P u}}{7+Z_{i}}\right)^{1 / 2}\right] f_{i}
$$

Through the use of Eq. (6) and Tables 4 and 6, the neutron yield for one gram of plutonium 238 and one part per million $(1 \mathrm{ppm})$ of each impurity has been calculated with the aid of a computer code; the results are presented in Table 7 . Since only the $\alpha$ particles emitted by ${ }^{238} \mathrm{Pu}$ are of concern, the disintegration constant $\lambda$ of this isotope is used. The half-life of ${ }^{238} \mathrm{Pu}$ is $86.4 \mathrm{yr}$, and $1 \mathrm{yr}$ is $3.15 \times 10^{7} \mathrm{~s}$. Therefore,

$$
\begin{aligned}
\lambda & =\frac{0.693}{T_{1 / 2}(\text { second })} \\
& =2.54 \times 10^{-10}(\text { second })^{-1} \\
\lambda N_{0} & =1.52 \times 10^{14} \text { second }^{-1} \text { mole }^{-1}
\end{aligned}
$$

If one takes $K$ as $81 \%{ }^{238} \mathrm{Pu}$ in the fuel, Eq. (8) can be rewritten in the form of $Y\left(\mathrm{~N} / \mathrm{g}^{238} \mathrm{Pu} / \mathrm{s} / \mathrm{ppm}\right)$ :

$$
1.2 \times 10^{8} \sum_{i}\left[\left(\frac{y_{0}}{A}\right)_{i}\left(\frac{Z_{i}}{Z_{P u}}\right)\left(\frac{7+Z_{P u}}{7+Z_{i}}\right)^{1 / 2}\right]
$$

for $1 \mathrm{ppm}$ of the $i$ th impurity; i.e., $f_{i}=1$. Table 7 summarizes the computer results obtained from this equation.

In the calculation of neutron yield, the experimental values obtained by Gorshkov (Ref. 14) were used. The absolute errors on the neutron yields given in Table 7 are about $1.5 \%$. This is due to the small errors given by Gorshkov.

The data in Table 7 indicate that the light elements such as $\mathrm{Be}, \mathrm{B}$, and $\mathrm{F}$ must be eliminated or minimized in the fuel to preclude large neutron emission rates. It should be noted that although the yield from oxygen per ppm is relatively low, the percent concentration of this element in $\mathrm{PuO}_{2}$ fuel is substantial and will tend to contribute sig-

\begin{tabular}{|c|c|c|c|c|c|c|c|}
\hline \multirow{2}{*}{ Element } & \multirow{2}{*}{$\mathbf{z}$} & \multirow{2}{*}{ A } & \multirow{2}{*}{$n / 10^{\circ} \alpha$} & \multirow{2}{*}{$\frac{S_{i}}{S_{P u}}$} & \multirow{2}{*}{$\left(\frac{y_{0}}{A}\right)$} & \multicolumn{2}{|c|}{$\frac{Y_{i}}{n / s / g}$} \\
\hline & & & & & & This work & $\begin{array}{l}\text { Matlack and } \\
\text { Metz (Ref. 6) }\end{array}$ \\
\hline Li & 3 & 7 & $2.6 \pm 1$ & 0.10 & $3.72 \times 10^{-1}$ & $4.64 \pm 1.78$ & 4.6 \\
\hline $\mathrm{Be}$ & 4 & 9 & $84.4 \pm 0.9$ & 0.13 & 9.35 & $148.80 \pm 1.55$ & 133 \\
\hline B & 5 & 11 & $19.6 \pm 0.2$ & 0.15 & 1.78 & $32.80 \pm 0.33$ & 41 \\
\hline c & 6 & 13 & $0.113 \pm 0.015$ & 0.18 & $8.7 \times 10^{-8}$ & $0.20 \pm 0.03$ & 0.2 \\
\hline 0 & 8 & 16 & $0.065 \pm 0.011$ & 0.20 & $4.27 \times 10^{-3}$ & $0.10 \pm 0.01$ & 0.1 \\
\hline $\mathbf{F}$ & 9 & 19 & $11.6 \pm 0.2$ & 0.24 & $6.10 \times 10^{-1}$ & $18.07 \pm 0.31$ & 18 \\
\hline $\mathrm{Na}$ & 11 & 23 & $1.5 \pm 0.4$ & 0.28 & $6.55 \times 10^{-2}$ & $2.22 \pm 0.58$ & 2.2 \\
\hline $\mathbf{M g}$ & 12 & 25 & $1.33 \pm 0.04$ & 0.29 & $5.33 \times 10^{-2}$ & $1.93 \pm 0.06$ & 2.1 \\
\hline AI & 13 & 28 & $0.76 \pm 0.03$ & 0.31 & $2.82 \times 10^{-2}$ & $1.08 \pm 0.04$ & 1.0 \\
\hline Si & 14 & 29 & $0.168 \pm 0.02$ & 0.32 & $5.8 \times 10^{-3}$ & $0.24 \pm 0.03$ & 0.2 \\
\hline $\mathbf{P}$ & - & - & - & - & - & - & $<0.03$ \\
\hline $\mathbf{s}$ & - & - & - & - & - & - & $<0.03$ \\
\hline
\end{tabular}
nificantly to the overall neutron yield. Clearly, for a given fuel source the neutron yield of each impurity should be calculated according to its contribution in parts per million to the overall fuel concentration. In the last column

Table 7. Neutron yield due fo $(\alpha, n)$ reactions with impurities in a ${ }^{238} \mathrm{Pu}_{\mathrm{i}}$ heat source ${ }^{\mathrm{a}}$

The definition of parameter $A$ and the value of $E_{\alpha}$ are given in Table 6. 
of Table 7, the results reported by Matlack and Metz (Ref. 6) are presented. Other experimental work in this area has been performed by E. D. Arnold (Ref. 16) and T. W. Bonner, A. A. Kraus, Jr., J. B. Morion, and J. P. Schiffer (Ref. 17).

\section{IV, Neutron Yield from $(\alpha, n)$ Reactions with ${ }^{18} \mathrm{O}$ Isotope}

When the fuel is made up of $\mathrm{PuO}_{2}$, the oxygen isotope plays an important part in the emission of neutrons via the ${ }^{18} \mathrm{O}(\alpha, n){ }^{21} \mathrm{Ne}$ reaction. The analysis of this interaction is given elsewhere (Refs. 13, 18, 19). In this section, the result of such a calculation is analyzed in terms of the total neutron yield.

In a hypothetical experiment it was assumed that the alpha particles from the ${ }^{238} \mathrm{Pu}$ isotope are allowed to interact with the oxygen isotope in the ${ }^{238} \mathrm{PuO}_{2}$ compound used as a nuclear power source. When an alpha particle enters into a nucleus, its energy dissipates among all nucleons. The excess energy brought in by the alpha particle will cause one or more nucleons to come to the surface and escape. The excited nucleus then emits a photon and returns to the ground state.

A $5.48-\mathrm{MeV}$ alpha particle is used at the start of the $(\alpha, n)$ reaction, and it is assumed that the energy loss takes place by ionization interaction with the target atoms. A computer code was developed (Ref. 19) to integrate Eq. (10) and to obtain the total neutron yield at a given neutron energy $E_{n}(k)$

$$
\begin{aligned}
& Y_{i} {\left[E_{n}(k)\right]=2.66 \times 10^{-7} \frac{N_{T}}{N_{o x}} X_{i} Y_{\alpha} } \\
& \times \int_{\left(E_{\alpha}\right) \text { th }}^{E_{\alpha_{\text {max }} \max }} \frac{E_{\alpha} \sigma_{m b}\left(E_{\alpha}\right)\left(\cos \theta_{k-1}^{*}-\cos \theta^{*} k\right) d E_{\alpha}}{8 \ln \left(5.62 E_{\alpha}\right)+47 \ln \left(0.547 E_{\alpha}\right)}
\end{aligned}
$$

where $N$ is the number density, $Y_{\alpha}$ is the $\alpha$-yield of the ${ }^{238} \mathrm{Pu}$ isotope, and $X_{i}$ is the probability of the decay of the $i$ th excited state of the ${ }^{21} \mathrm{Ne}$ recoil nucleus (Ref. 20).

Since $N_{T} / N_{o x}=1.815 \times 10^{-3}$, Eq. (10) may be rewritten in the form of

$$
Y_{i}\left[E_{n}(k)\right]=4.82 \times 10^{-10} X_{i} Y_{\alpha} I_{i}\left(E_{\alpha, \max } ; E_{\alpha, t h}^{i}\right)
$$

where $I_{i}$ is the value of the integral given in Eq. (10). Table 8 presents different values of the decay probability, alpha particle threshold energy, Q-value, and, finally, the maximum energy of the emitted neutrons for each excited state of the recoil nucleus. In Eq. (11), the neutron yield $Y_{i}$ and the $\alpha$-yield $Y_{\alpha}$ are given in N/s/g ${ }^{238} \mathrm{Pu}$ and $\alpha / \mathrm{s} / \mathrm{g}$

\begin{tabular}{|c|c|c|c|c|c|}
\hline $\begin{array}{l}\text { Excifed stafes of } \\
{ }^{21} \mathrm{Ne} \text { isotope }\end{array}$ & $\mathrm{E}, \mathrm{MeV}$ & $\begin{array}{c}\text { Probability } \\
\text { (Ref. 20), } \\
\%\end{array}$ & Q, MeV & $\begin{array}{l}\left(E_{\alpha}\right)_{\text {th }} \\
\mathrm{MeV}\end{array}$ & $\begin{array}{c}\left(E_{n}\right)_{\max } \\
\operatorname{MeV}\end{array}$ \\
\hline Ground state & 0.0 & 55 & -0.704 & 0.86 & 4.48 \\
\hline $\begin{array}{l}\text { First excited } \\
\text { stale }\end{array}$ & 0.349 & 35 & -1.049 & 1.28 & 4.11 \\
\hline $\begin{array}{l}\text { Second excited } \\
\text { state }\end{array}$ & 1.75 & $\sim 10$ & -2.45 & 3.00 & 2.60 \\
\hline $\begin{array}{l}\text { Third excited } \\
\text { state }\end{array}$ & 2.87 & $\sim 1$ & -3.57 & 4.36 & 1.33 \\
\hline
\end{tabular}

Table 8. Excited states of the recoil isotope in ${ }^{18} \mathrm{O}(\alpha, n)^{21} \mathrm{Ne}$ reaction

${ }^{238} \mathrm{Pu}$, respectively. Therefore, the number of neutrons per alpha per $\mathrm{MeV}$ from the $i$ th excited state of the ${ }^{21} \mathrm{Ne}$ isotope produced in ${ }^{18} \mathrm{O}(n, \alpha){ }^{21} \mathrm{Ne}$ reaction is

$$
\eta_{i}=4.82 \times 10^{-10} X_{i} I_{i}\left(E_{\alpha}\right)
$$

Figure 2 presents different values of the function $\eta_{i}$ in terms of the emitted neutron energy $E_{n}$ for each excited

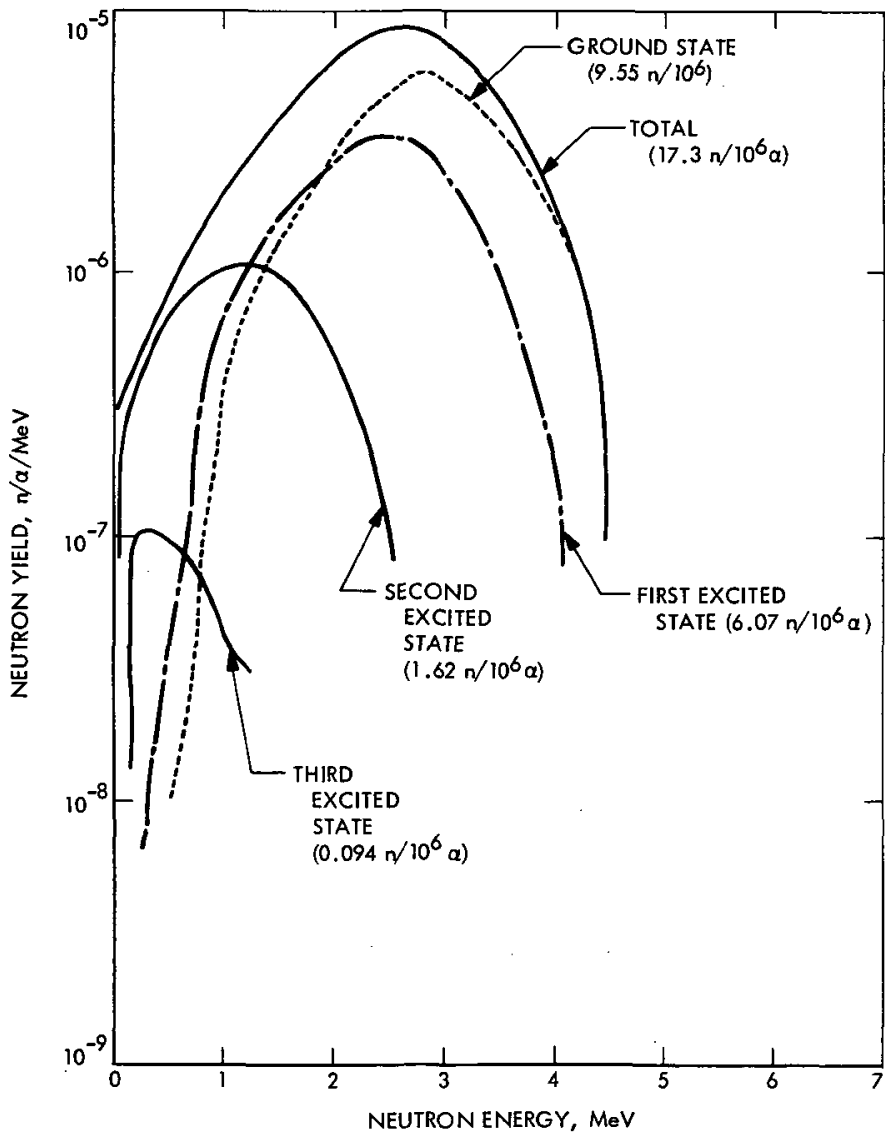

Fig. 2. Weighted neutron yield from ${ }^{18} \mathrm{O}(\alpha, n)^{21} \mathrm{Ne}$ reactions 
state of the recoil. The area under each curve represents the number of neutrons emitted per $\alpha$ particle interacted. The sum of the areas gives the total neutron yield for the reaction. ${ }^{3}$ From this analysis one may obtain the neutron yield for the $(\alpha, n)$ reaction in a $\mathrm{PuO}_{2}$ nuclear power source (Fig. 2 and Ref. 18).

As far as the experimental values are concerned, consider first the shape of the yield spectrum. One such experiment was performed at the Savannah River Laboratory (SRL, Ref. 21). Figure 3 presents the result of the JPL calculation and adjusted measured data (shown as the dotted curve). One can easily notice a discrepancy between the two in the low-energy range, namely, below a $1-\mathrm{MeV}$ neutron energy. It has been explained (Ref. 21) that these low-energy neutrons are due to the scattering and multiplication in the fuel itself.

In order to investigate the source of these neutrons the SRL neutron source geometry and the FASTER Monte Carlo code (Ref. 22) have been used to obtain the fraction of neutrons scattered in the source. Figure 4 shows three neutron fluxes, all calculated by using the Monte Carlo code and the computed neutron source. A significant dif'ference can be noted when the unscattered flux is compared with the scattered flux obtained when neutrons are allowed to scatter five times. It can be seen from Fig. 4

${ }^{3}$ For more detailed discussions, Refs. 18 and 19 should be consulted.

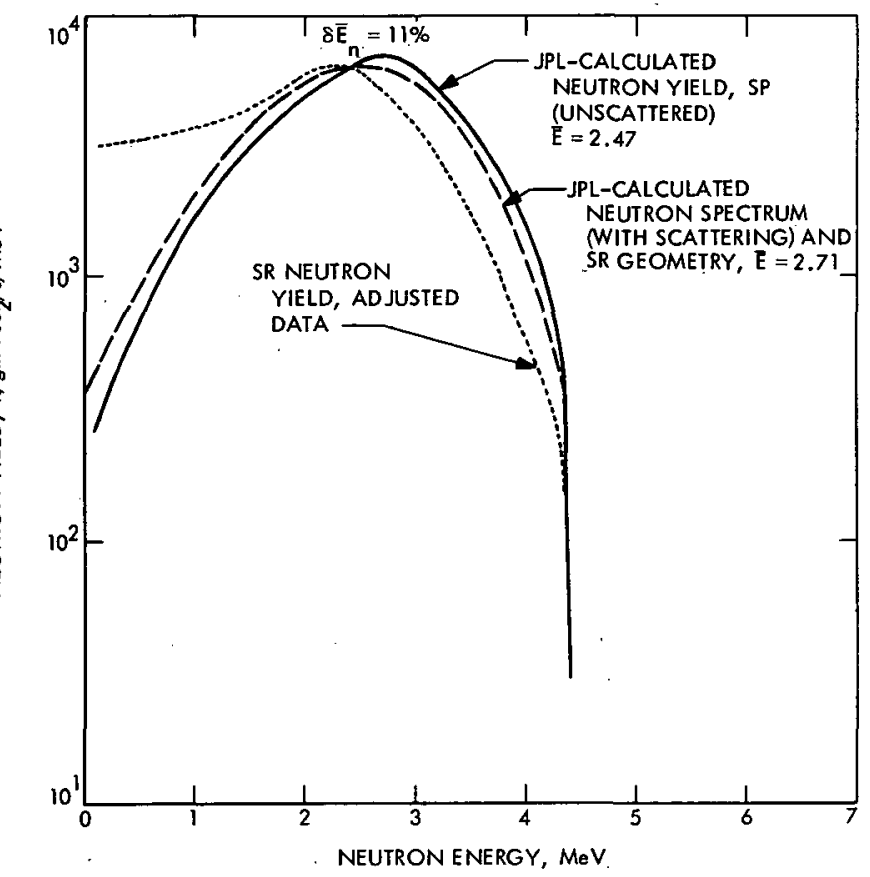

Fig. 3. Neuiron yield from the SRL experiment that if the number is allowed to increase to 15 scatterings no major difference is observed. By use of the unscattered flux, the fraction of neutrons scattered as a function of energy is obtained. This scattering percent can now be folded into the computed neutron yield and compared with the experimental value shown in Fig. 3. In the comparison, note that the high-intensity, low-energy neutrons cannot be accounted for by the scattering of the neutrons in the fuel.

In addition, the average path length of neutrons can be estimated to be about $2 \mathrm{~cm}$, and the average energy change due to each neutron scattering is about $10 \%$. Since the diameter of the fuel geometry used by SRL is also $2 \mathrm{~cm}$, one cannot expect a large number of neutrons to be scattered and lose a lot of energy; this probably cannot account for the high intensity of neutrons in the lowenergy range.

One may account for these low-energy neutrons as being due to the thermal neutrons which are, for example,

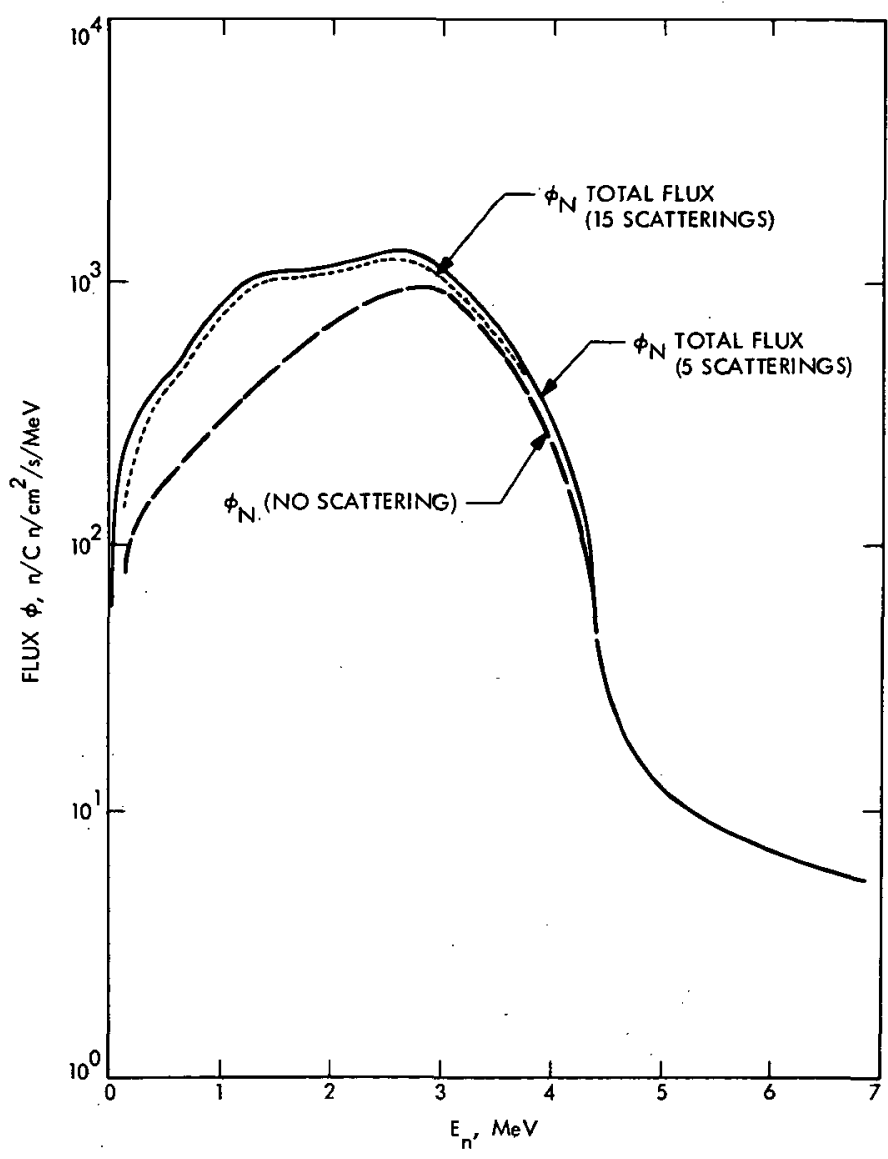

Fig. 4. Monte Carlo result calculated for the SRL geometry with JPL neutron yield spectrum 
created around the experimental apparatus. This is made more pronounced by the fact that the detector selected for this experiment was a lithium detector which has a high $Q$-value; thus it is overbiased toward low-energy neutrons.

In order to compare the integrated value of the neutron yield spectrum with the experimental data, one has to obtain the area under each curve (Fig. 2) and then sum them all up.

Figure 2 presents the weighted neutron yield $(n / \alpha)$ from each of the excited states of the ${ }^{21} \mathrm{Ne}$-isotope considered. The total integrated values for each of these states are also shown in Fig. 2; they are $9.55 n / 10^{6} \alpha$ for the ${ }^{21} \mathrm{Ne}$ ground state and 6.07, 1.62, and $0.094 n / 10^{6} \alpha$ for the first three excited states. Thus a total of $(17.33 \pm 4.0) n / 10^{6} \alpha$ is obtained from ${ }^{238} \mathrm{Pu}^{18} \mathrm{O}_{2}$ when the contributions from all the states are added together.

The magnitude of the error on the total neutron yield is due to the errors on the reaction cross section measured by Bair and Willard (Ref. 23). Their value for the cross section at the peak of the $3.19 \mathrm{MeV}$ resonance is $(109 \pm 25) \mathrm{mb}$.

It can be noted that usually the measurements have been performed on the $\mathrm{PuO}_{2}$ fuel, where $\mathrm{Pu}$ contains all of the plutonium isotopes of which $81 \%$ is the ${ }^{238} \mathrm{Pu}$ isotope. Since the fractional weight of $\mathrm{Pu}$ in $\mathrm{PuO}_{2}$ is equal to 0.8814 , the fractional weight of ${ }^{238} \mathrm{Pu}$ in $\mathrm{PuO}_{2}$ is equal to 0.714 . The fraction of ${ }^{18} \mathrm{O}$ in the oxygen is $1.815 \times 10^{-3}$; thus the neutron yield from the $\mathrm{PuO}_{2}$. source is equal to $(2.24 \pm 0.51) \times 10^{-8} n / \alpha$.

Table 9. Neutron yield comparison in the ${ }^{18} \mathrm{O}(\alpha, n)^{21} \mathrm{Ne}$ reaction

\begin{tabular}{|c|c|c|c|}
\hline Source & ${ }_{10} / \mathrm{s} / \mathrm{g}^{258} \mathrm{Pu}$ & 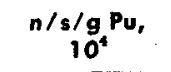 & n/s/g $\mathrm{PuO}_{2}$ \\
\hline $\begin{array}{l}\text { This work } \\
Y_{\alpha}=6.35 \times 10^{11} \\
(\text { Ref. 6) }\end{array}$ & $(1.99 \pm 0.45)$ & $(1.67 \pm 0.38)$ & $(1.42 \pm 0.32)$ \\
\hline $\begin{array}{l}\text { This work } \\
Y_{\alpha}=5.11 \times 10^{11} \\
\text { (Ref. 9) }\end{array}$ & $(1.60 \pm 0.37)$ & $(1.34 \pm 0.31)$ & $(1: 14 \pm 0.26)$ \\
\hline $\begin{array}{l}\text { Matlack and Metz } \\
\text { (Ref. 6) }\end{array}$ & - & - - & $(1.00 \pm 0.02)$ \\
\hline $\begin{array}{l}\text { Anderson and Neff } \\
\text { (Ref. 2) }\end{array}$ & $(2-3)$. & $(2.2 \pm 0.1)$ & - \\
\hline $\begin{array}{l}\text { Stoddard and } \\
\text { Albensius } \\
\text { (Ref. 9) }\end{array}$ & - & 2.1 & 1.9 \\
\hline
\end{tabular}

The number of $\alpha$ particles per gram of plutonium 238 per second, the $\alpha$-yield, is (Ref. 6) $6.35 \times 10^{11}$; therefore, the total neutron yield from the $(\alpha, n)$ interaction with oxygen is $(1.42 \pm 0.32) \times 10^{4} \mathrm{n} / \mathrm{g} \mathrm{PuO}_{2} / \mathrm{s}$. An experimental value given by the Los Alamos group is $(1.0 \pm 0.02) \times 10^{4}$ $\mathrm{n} / \mathrm{g} \mathrm{PuO}_{2} / \mathrm{s}$ which is in good agreement with the computed result given here.

Moreover, if a value of $5.11 \times 10^{11}$ is used (Ref. 9) for the $\alpha$-yield of ${ }^{238} \mathrm{Pu}$, the calculated value will be equal to $(1.14 \pm 0.26) \times 10^{4} \mathrm{n} / \mathrm{g} \mathrm{PuO}_{2} / \mathrm{s}$, and the agreement will be even better. These results are presented in Table 9 .

\section{The Overall Neutron Yield and Flux from $\mathrm{PuO}_{2}$ Fuel}

In the previous sections some of the schemes which may be used to obtain the partial neutron yield and yield spectrum from a $\mathrm{PuO}_{2}$ fuel power source were indicated. The physical phenomena behind the emission of the neutrons from such a source are the spontaneous fission, induced fission, and $(\alpha, n)$ reactions with impurities in the fuel.

The only natural neutron radiation of this fuel source is the spontaneous fission; however, the presence of impurities in the fuel makes the problem more complex. Presented in this section is a way to add the neutron yield spectra of all these sources together and, for a typical multihundred-watt power source, determine the neutron flux at various observation points outside the geometry of the source.

\section{A. Total Neutron Source}

The total neutron source for a given fuel depends upon the percent impurities in the fuel. If the fuel is free of any impurities which contribute to the total neutron yield and if the ${ }^{18} \mathrm{O}-{ }^{17} \mathrm{O}$ isotopes are eliminated or reduced to a negligible amount, the total neutron yield spectrum is identical to the spontaneous fission yield. If all the contributing impurities are removed and the ${ }^{18} \mathrm{O}$ isotope is left in the fuel, the total neutron yield spectrum will be equal to the sum of the spontaneous fission yield and the $(\alpha, n)$ reaction with oxygen. Such a result is presented in Table 10, where the computed results and the measured values reported by the Los Alamos group (Ref. 24) are also shown.

In the case where not all other additive impurities are removed, one has to know the exact ppm contamination of these impurities. Since only the low- $Z$ impurities need be 
Table 10. Neutron yield from a $\mathrm{PuO}_{2}$ fuel power source (n/g $\left.\mathrm{PuO}_{2} / \mathrm{s}\right)$

\begin{tabular}{lccc}
\hline Source & $\begin{array}{c}\text { Spontaneous } \\
\text { fission, } \\
10^{3}\end{array}$ & $\begin{array}{c}(\alpha, n) \text { with } \\
\text { oxygen, } \\
10^{4}\end{array}$ & $\begin{array}{c}\text { Total, } \\
10^{4}\end{array}$ \\
\hline $\begin{array}{c}\text { JPL: } Y_{\alpha}\left({ }^{238} \mathrm{Pu}\right)= \\
6.35 \times 10^{11} \\
(\text { Ref. } 6)\end{array}$ & $(1.96 \pm 0.10)$ & $(1.42 \pm 0.32)$ & $(1.62 \pm 0.37)$ \\
$\begin{array}{c}\text { JPL: } Y_{\alpha}\left({ }^{238} \mathrm{Pu}\right)= \\
5.11 \times 10^{11} \\
(\text { Ref. } 9)\end{array}$ & $(1.96 \pm 0.10)$ & $(1.14 \pm 0.26)$ & $(1.34 \pm 0.31)$ \\
$\begin{array}{l}\text { Los Alamos } \\
\text { experimental } \\
\text { (Ref. 24) }\end{array}$ & $(2.20 \pm 0.04)$ & $(1.00 \pm 0.02)$ & $(1.22 \pm 0.02)$ \\
\hline The $Y_{\alpha}$ is the ${ }^{238} \mathrm{Pu} \alpha$ yield given in $\alpha / 9{ }^{288} \mathrm{Pu} / \mathrm{s}$. & \\
\hline
\end{tabular}

considered (Section III), the problem becomes somewhat simplified; that is, the high- $Z$ impurities do not contribute to the overall neutron yield from a $\mathrm{PuO}_{2}$ power source unless they contain oxygen. In such cases the oxygen portion of the impurity can be treated as an impurity, and the neutron yield contribution can be evaluated via $(\alpha, n)$ reactions with oxygen.

In addition, the neutron yield from impurities emitted by spontaneous fission or $(\alpha, n)$ reactions, where the $\alpha$ particle is emitted from the impurities, should not be considered as a major source, basically because of a very low percent contamination of these undesirable impurities in the fuel. The enhancement of the total neutron yield from these sources is much less than $1 \%$. In order to calculate the total neutron yield, including the contribution from the impurities, a typical multihundred-watt (MHW) fuel capsule with the contaminating impurities shown in Table 11 has been selected. Using the neutron yield/ppm

Table 11. Fractions of low- $Z$ impurities in a 2.2-kW(thermall $\mathrm{PuO}_{2}$ fuel power source

\begin{tabular}{|c|c|c|c|}
\hline $\begin{array}{l}\text { Impurity } \\
\text { elements }\end{array}$ & $\begin{array}{c}\text { Impurities in } \\
\mathrm{PuO}_{2,}, \mathrm{ppm}\end{array}$ & $\begin{array}{c}\text { Yield/ppm, } \\
\text { n/g PuO } / \mathrm{s} / \mathrm{ppm}\end{array}$ & Yield \\
\hline $\mathbf{l i}$ & 1 & 4.64 & 4.64 \\
\hline $\mathrm{Be}$ & 10 & 148.80 & 1488.00 \\
\hline B & -20 & 32.80 & 656.00 \\
\hline$c$ & 500 & 0.20 & 100.00 \\
\hline 0 & $11,750^{\mathrm{a}}$ & 0.10 & 1175.00 \\
\hline $\mathbf{F}$ & $250^{\circ}$ & 18.70 & 4517.50 \\
\hline $\mathrm{Na}$ & 300 & 2.00 & 600.00 \\
\hline $\mathrm{Mg}$ & 50 & 1.93 & 96.50 \\
\hline Al & 400 & 1.08 & 432.00 \\
\hline $\mathbf{s i}$ & 441 & 0.240 & 105.84 \\
\hline Olhers & 1200 & 0.03 & $\begin{array}{c}36.00 \\
9211.50 \pm 138.2\end{array}$ \\
\hline
\end{tabular}

- Oxygen content of the fuel other than the $\mathrm{PuO}_{2}$. for each impurity, one can estimate the total integrated neutron yield for this source at slightly less than $10^{4} \mathrm{n} / \mathrm{g}$ $\mathrm{PuO}_{2} / \mathrm{s}$. If the neutron yield spectrum due to the $(\alpha, n)$ reaction with oxygen is used for the neutron yield spectrum due to the $(\alpha, n)$ reactions with other impurities, the total neutron yield spectrum can be computed by adding the three spectra together. The result of such a computation is shown in Fig. 5.

The neutron yields per gram of $\mathrm{PuO}_{2}$ per second for spontaneous fission and $(\alpha, n)$ reaction with oxygen and other impurities are shown in Fig. 5. The total neutron yield spectrum is then obtained by adding the neutron spectra mentioned above. The average neutron energy is equal to $2.48 \mathrm{MeV}$. When the induced fission neutron and scattering within the neutron source are included, this average energy is reduced to $2.28 \mathrm{MeV}$. For any other fuel power source design, the ppm impurities have to be evaluated first; a new neutron yield due to the impurities can then be easily calculated from Table 11.

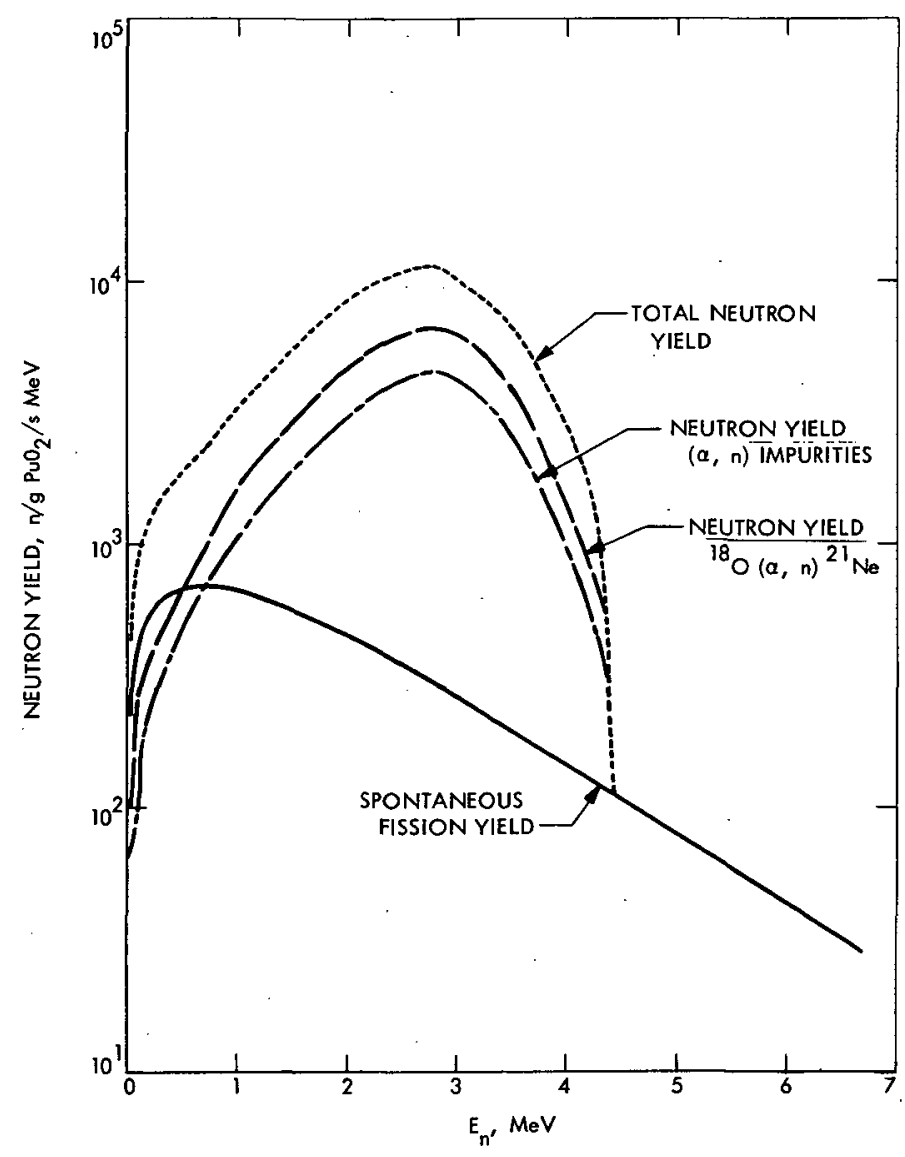

Fig. 5. Total neutron yield from a 2.2-kW-MHW $\mathrm{PuO}_{2}$ source 


\section{B. Neutron flux from a MHW Fuel Capsule}

The total neutron yield spectrum obtained in the previous sections for a given source can now be used to calculate the neutron flux. As was pointed out previously, a 2200-W (thermal) MHW fuel capsule was chosen for this calculation as a typical neutron source. The geometry of such a source is shown in Fig. 6. The dimensions of the source and shielding materials are also shown. The fuel volume is about $707 \mathrm{~cm}^{3}$, the power density is $3.11 \mathrm{~W}$ (thermal) $/ \mathrm{cm}^{3}$, and the specific power is $0.39 \mathrm{~W}$ (ther$\mathrm{mal}) / \mathrm{g} \mathrm{PuO}_{2}$. The two areas of observation are at 50 and $100 \mathrm{~cm}$ away from the center of the source, and in each segment three points are used. The point at the center is $45 \mathrm{deg}$ apart from the other two points at the opposite corners.

Points 1 and 2 are located right at the outside of the shielding material and about $2 \mathrm{~cm}$ away from the source itself. These two points are the nearest points to the source for which the flux calculation is made.

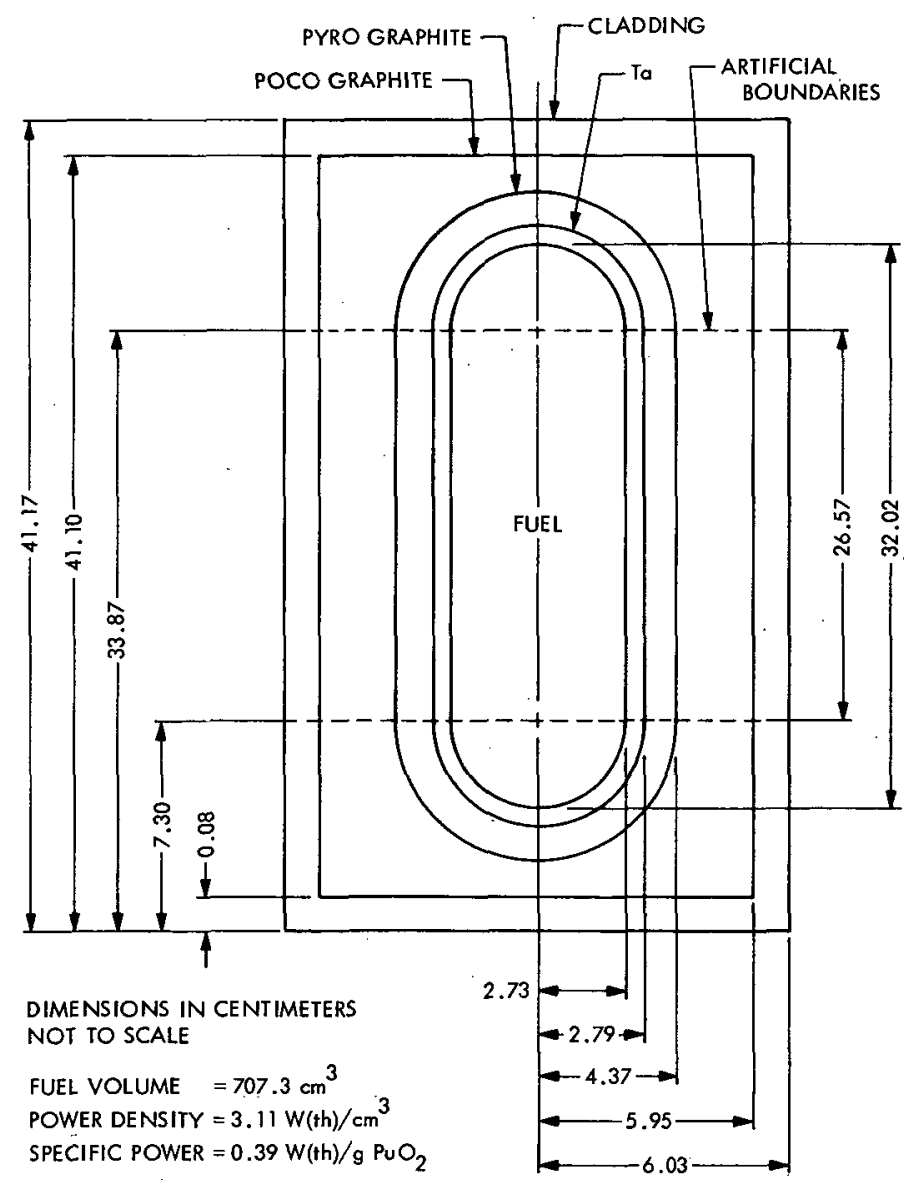

Fig. 6. The geometry setup of the 2.2-kW-MHW $\mathrm{PuO}_{2}$ fuel capsule
1. Neutron multiplication. The real neutron source is different from an extremely thin disk-like hypothetical source because induced fission and scattering can occur. These induced fission neutrons are created in the same fashion that the spontaneous fission neutrons are emitted. Therefore, additional neutrons are emitted via induced fission, and the overall neutron yield is increased by a multiplication factor (MF). Because the shape of the induced fission spectrum is the same as the spontaneous fission spectrum, one may simply add them together.

If $Y_{t}$ is the total integrated neutron yield when the induced fission is included and $Y_{0}$ when the induced fission $Y_{i f}$ is not included, then $Y_{t}$ is given by

$$
Y_{t} \equiv Y_{0}+Y_{i \prime}
$$

and

$$
Y_{0}=Y(\alpha, n)+Y_{1}
$$

For the $i$ th neutron energy interval the corresponding relationship will be

$$
Y_{t}(i)=\left[\left(Y_{t} Y_{0}^{-1}-1\right) Y_{0} Y_{f}^{-1}\right] Y_{f}(i)+Y_{0}(i)
$$

where $Y_{f}$ and $Y_{i f}$ are the neutron yields for the spontaneous and the induced fission, respectively. Using Eq. (14) one can obtain the total neutron yield spectrum including the induced fission neutrons. The only parameter which is not known is $Y_{t} Y_{0}^{-1}$ or the multiplication factor which has to be calculated by utilization of a transport code. Such a computer code has been developed by Atomics International and is called ANISN (Ref. 25). It is used to obtain a diffusion solution of the transport equation utilizing a first-order iteration technique.

After feeding the geometry of the MHW neutron source and $Y_{0}$, the neutron yield, into the ANISN code, a multiplication factor of 1.81 was calculated for this source. The reason for such a high multiplication factor has to do with the number density of the fuel, the surface-to-volume ratio, and the quantity of graphite used for shielding purposes. Graphite causes the slowing down of neutrons and consequently increases the induced fission neutron yield. For this configuration of the fuel geometry the corresponding $K_{e f f}$ is equal to 0.448 . This means the induced fission is about $44.8 \%$ of the total neutron yield. If the graphite is removed, the ANISN code gives a. $K_{\text {eff }}$ of 0.353 , which corresponds to a multiplication factor of 1.55 . This factor is about $20 \%$ larger than the VIKING SNAP 19 multiplication factor obtained from the ANISN code. The SNAP 19, of course, has only $675 \mathrm{~W}$ (thermal), in comparison with the $2200 \mathrm{~W}$ and a much smaller density and 


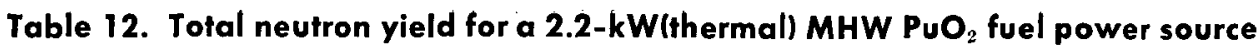

\begin{tabular}{|c|c|c|c|c|}
\hline \multirow{2}{*}{$\begin{array}{c}\text { Neutron } \\
\text { energy, } \\
\text { MeV }\end{array}$} & \multicolumn{2}{|c|}{$\begin{array}{c}\text { Neutron yield, } \\
\text { n/s/g PuO }\end{array}$} & \multicolumn{2}{|c|}{$\begin{array}{c}\text { Neutron yield spectrum, } \\
n / \mathrm{s} / \mathrm{g} \mathrm{PuO}_{2} / \mathrm{MeV}\end{array}$} \\
\hline & Total & $\begin{array}{c}\text { Total } \\
\text { effective }\end{array}$ & Total & $\begin{array}{c}\text { Total } \\
\text { effective }^{a}\end{array}$ \\
\hline$(2.05-10) \times 10^{-8}$ & $2.53 \times 10^{-8}$ & $2.90 \times 10^{-7}$ & $3.36 \times 10^{-1}$ & $3.37 \times 10^{\circ}$ \\
\hline$(1.00-30) \times 10^{-7}$ & $4.21 \times 10^{-6}$ & $4.85 \times 10^{-6}$ & $1.45 \times 10^{0}$ & $1.67 \times 10^{1}$ \\
\hline$(3.00-30) \times 10^{-6}$ & $1.37 \times 10^{-4}$ & $1.58 \times 10^{-3}$ & $5.07 \times 10^{\circ}$ & $5.84 \times 10^{x}$ \\
\hline$(3.00-55.5) \times 10^{-5}$ & $2.12 \times 10^{-2}$ & $1.34 \times 10^{-1}$ & $4.04 \times 10^{1}$ & $2.55 \times 10^{2}$ \\
\hline$(5.55-170) \times 10^{-4}$ & $2.83 \times 10^{0}$ & $2.14 \times 10^{1}$ & $1.72 \times 10^{2}$ & $1.30 \times 10^{3}$ \\
\hline$(1.70-4.49) \times 10^{-2}$ & $1.14 \times 10^{1}$ & $8.08 \times 10^{1}$ & $4.08 \times 10^{2}$ & $2.90 \times 10^{3}$ \\
\hline $0.0449-0.122$ & $6.22 \times 10^{1}$ & $3.93 \times 10^{2}$ & $8.07 \times 10^{2}$ & $5.09 \times 10^{3}$ \\
\hline $0.122-0.201$ & $8.29 \times 10^{1}$ & $4.97 \times 10^{2}$ & $.1 .05 \times 10^{3}$ & $6.30 \times 10^{3}$ \\
\hline $0.201-0.331$ & $1.70 \times 10^{2}$ & $9.93 \times 10^{2}$ & $1.31 \times 10^{3}$ & $7.64 \times 10^{3}$ \\
\hline $0.331-0.546$ & $3.51 \times 10^{2}$ & $1.85 \times 10^{3}$ & $1.63 \times 10^{3}$ & $8.58 \times 10^{3}$ \\
\hline $0.546-0.702$ & $3.08 \times 10^{2}$ & $1.46 \times 10^{3}$ & $1.98 \times 10^{3}$ & $9.33 \times 10^{3}$ \\
\hline $0.702-0.900$ & $5.09 \times 10^{2}$ & $1.95 \times 10^{3}$ & $2.57 \times 10^{3}$ & $9.35 \times 10^{3}$ \\
\hline $0.900-1.16$ & $8.84 \times 10^{2}$ & $2.70 \times 10^{3}$ & $3.40 \times 10^{3}$ & $1.04 \times 10^{4}$ \\
\hline $1.16-1.49$ & $1.52 \times 10^{3}$ & $3.60 \times 10^{3}$ & $4.59 \times 10^{3}$ & $1.09 \times 10^{4}$ \\
\hline $1.49-1.91$ & $2.69 \times 10^{3}$ & $4.98 \times 10^{3}$ & $6.41 \times 10^{3}$ & $1.19 \times 10^{4}$ \\
\hline $1.91-2.45$ & $5.28 \times 10^{3}$ & $7.63 \times 10^{8}$ & $9.78 \times 10^{3}$ & $1.41 \times 10^{4}$ \\
\hline $2.45-3.14$ & $7.67 \times 10^{3}$ & $9.84 \times 10^{3}$ & $1.11 \times 10^{4}$ & $1.43 \times 10^{4}$ \\
\hline $3.14-4.04$ & $5.13 \times 10^{3}$ & $6.94 \times 10^{3}$ & $5.70 \times 10^{3}$ & $7.71 \times 10^{3}$ \\
\hline $4.04-4.46$ & $5.26 \times 10^{2}$ & $1.07 \times 10^{3}$ & $1.25 \times 10^{3}$ & $2.55 \times 10^{3}$ \\
\hline $4.46-5.18$ & $6.30 \times 10^{1}$ & $7.26 \times 10^{2}$ & $8.75 \times 10^{1}$ & $1.01 \times 10^{3}$ \\
\hline $5.18-6.66$ & $6.86 \times 10^{2}$ & $7.90 \times 10^{2}$ & $4.64 \times 10^{1}$ & $5.34 \times 10^{2}$ \\
\hline $6.66-8.55$ & $3.23 \times 10^{1}$ & $3.72 \times 10^{2}$ & $1.71 \times 10^{1}$ & $1.97 \times 10^{2}$ \\
\hline $8.55-10.00$ & $6.95 \times 10^{0}$ & $8.01 \times 10^{1}$ & $4.79 \times 10^{\circ}$ & $5.52 \times 10^{1}$ \\
\hline $\begin{array}{c}\text { Total } \\
\text { Average } E_{n}\end{array}$ & $\begin{array}{l}2.54 \times 10^{4} \\
2.48\end{array}$ & $\begin{array}{l}4.59 \times 10^{4} \\
2.28\end{array}$ & & \\
\hline
\end{tabular}

"When the induced fission is included.

volume/surface ratio. It should be emphasized that the ANISN code is one-dimensional, and consequently the margin of error is substantial.

2. Flux calculation. By using the procedure described above, the total neutron yield and yield spectrum were calculated for the 2200-W MHW fuel capsule and are presented in Table 12. Having obtained the total neutron yield from the MHW fuel power source, the Monte Carlo code now can be applied to calculate the neutron flux at various observation points shown in Fig. 6. The FASTER Monte Carlo (Ref. 22) code was selected for this computation.

In Table 13 the total number and energy flux of the selected detector points are shown. In addition, in Fig. 7 the flux spectrum of the detector is presented. Clearly, for points 1 and 2 (i.e., closest points to the shield) the $1 / R^{2}$ falloff hypothesis does not hold; for the points much farther away from the source, the $1 / R^{2}$ falloff may be utilized to obtain the flux. Thus the integrated values of neutron flux need to be calculated only for the smaller region surrounding the source (i.e., about $50 \mathrm{~cm}$ ). For the
Table 13. Neutron flux at nine detector points

\begin{tabular}{crrccc}
\hline $\begin{array}{c}\text { Defector } \\
\text { points }\end{array}$ & $\begin{array}{c}\text { d, } \\
\mathbf{c m}\end{array}$ & $\begin{array}{c}\theta_{\text {f }} \\
\text { deg }\end{array}$ & $\begin{array}{c}\phi_{n} \\
\mathrm{n} / \mathrm{cm}^{2} / \mathrm{s}\end{array}$ & $\begin{array}{c}\phi_{E,} \\
\mathrm{MeV} / \mathrm{cm}^{2} / \mathrm{s}\end{array}$ & $\begin{array}{c}\mathrm{E}_{n_{1}} \\
\mathrm{MeV}\end{array}$ \\
\hline 1 & 6 & 0 & $1.25 \times 10^{5}$ & $2.56 \times 10^{5}$ & 2.06 \\
2 & 10 & 90 & $4.83 \times 10^{4}$ & $8.75 \times 10^{4}$ & 2.06 \\
3 & 50 & 0 & $5.43 \times 10^{3}$ & $1.08 \times 10^{4}$ & 2.00 \\
4 & 50 & 45 & $3.73 \times 10^{3}$ & $7.55 \times 10^{3}$ & 2.02 \\
5 & 50 & 90 & $1.45 \times 10^{3}$ & $3.10 \times 10^{3}$ & 2.14 \\
6 & 100 & 0 & $1.39 \times 10^{3}$ & $2.77 \times 10^{3}$ & 2.00 \\
7 & 100 & 45 & $9.10 \times 10^{2}$ & $1.84 \times 10^{3}$ & 2.03 \\
8 & 100 & 90 & $2.62 \times 10^{2}$ & $5.70 \times 10^{2}$ & 2.18 \\
\hline 9 & 25 & 45 & $1.80 \times 10^{4}$ & $3.60 \times 10^{4}$ & 2.00 \\
\hline
\end{tabular}

approximate values of the neutron flux beyond these points (first five points), $1 / R^{2}$ falloff can be easily applied (Ref. 19).

\section{Results and Conclusion}

The total integrated neutron yield and spectrum have been calculated for a MHW fuel power source with induced fission included. The multiplication factor was 


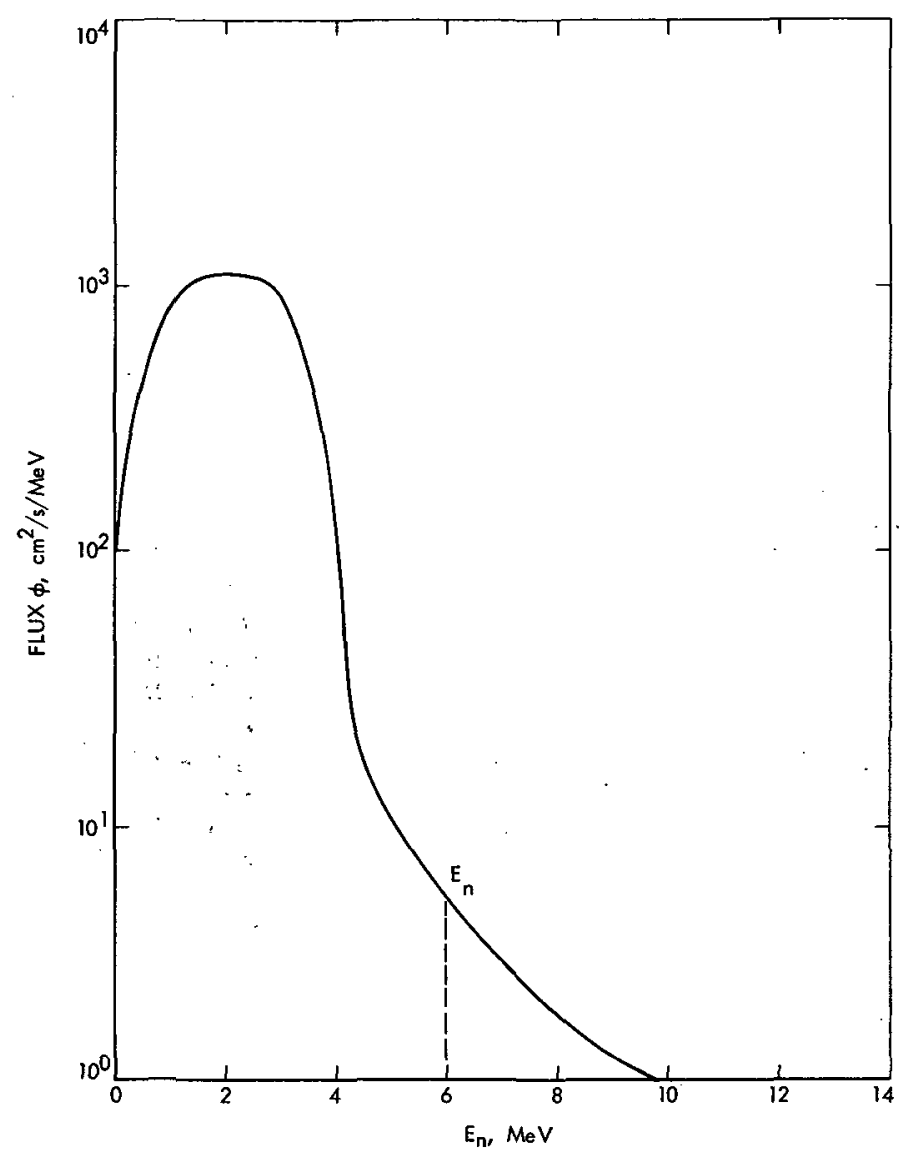

Fig. 7. Neutron flux spectrum af $50-\mathrm{cm}$ away from the 2.2-kW $\mathrm{PuO}_{2}$ fuel capsule

calculated by using the ANISN transport code. The total neutron yield spectrum and the physical geometry of a 2.2-kW(thermal) MHW source were fed into the Monte Carlo code to obtain the neutron flux and the neutron flux spectrum at various points outside the fuel. It is concluded that, beyond $50 \mathrm{~cm}$, a point source assumption can be used. For neutron fluxes at these large distances the $1 / R^{2}$ falloff can be used with confidence.

Calculations have indicated a total of $2.54 \times 10^{4} \mathrm{n} / \mathrm{s} / \mathrm{g}$ $\mathrm{PuO}_{2}$ when the induced fission neutrons are not included. This yield consists of $1.95 \times 10^{3} \mathrm{n} / \mathrm{s} / \mathrm{g} \mathrm{PuO}_{2}$ due to the spontaneous fission, $1.42 \times 10^{4} \mathrm{n} / \mathrm{s} / \mathrm{g} \mathrm{PuO}_{2}$ due to the $(\alpha, n)$ reactions with oxygen in $\mathrm{PuO}_{2}$, and $9.21 \times 10^{3} \mathrm{n} / \mathrm{s} / \mathrm{g}$ $\mathrm{PuO}_{2}$ due to the $(\alpha, n)$ reactions with all other impurities. The induced fission neutron yield for this typical fuel power source is equal to $2.05 \times 10^{4} \mathrm{n} / \mathrm{s} / \mathrm{g} \mathrm{PuO}_{2}$. Therefore, by adding the induced fission neutron yield to the total neutron yield, a grand total of $4.59 \times 10^{4} \mathrm{n} / \mathrm{s} / \mathrm{g} \mathrm{PuO}_{2}$ is obtained. In order to obtain these neutron yields in terms of ${ }^{238} \mathrm{Pu}$ rather than $\mathrm{PuO}_{2}$, the above numbers should be multiplied by $1 / 0.714$.

From these data it is concluded that $4.2 \%$ of the neutrons are emitted because of spontaneous fission, $31 \%$ via the $(\alpha, n)$ reaction with oxygen in $\mathrm{PuO}_{2}, 20 \%$ via $(\alpha, n)$ reactions with impurities in this fuel configuration, and, finally, $44.8 \%$ via induced fission. The $K_{e f f}$ is calculated to be equal to $\mathbf{0 . 4 4 8}$, which gives a multiplication factor of 1.81 .

The total neutron rate from a 2.2-kW-MHW source may be obtained by multiplying the neutron yield $\left(4.59 \times 10^{4} \mathrm{n} / \mathrm{s} / \mathrm{g} \mathrm{PuO}_{2}\right)$ by the total mass of the $\mathrm{PuO}_{2}$ fuel $(2200 / 0.39=5.65 \mathrm{~kg})$. The neutron rate is thus equal to $2.60 \times 10^{8} \mathrm{n} / \mathrm{s}$. Moreover, for $2-\mathrm{MeV}$ neutrons a $1 \mathrm{mrem} / \mathrm{h}$ dose rate is produced by $8.7 \mathrm{n} / \mathrm{cm}^{2} / \mathrm{s}$ (dose rate conversion factor); therefore, at any detector point (Table 12), the total dose rate may be calculated. For example, at $100 \mathrm{~cm}$ distance from the source (i.e., detector point 7) the number flux is $910 \mathrm{n} / \mathrm{cm}^{2} / \mathrm{s}$, and the total dose rate at this location is $104 \mathrm{mrem} / \mathrm{h}$. 


\section{References}

1. Grundle, J. A., Study of Fission Spectra with High-Energy Activation Detector, MS 2883, Los Alamos Scientific Laboratory, Los Alamos, N. Mex., May 20, 1963.

2. Anderson, M. E., and Neff, R. A. "Neutron Emission Rates and Energy Spectra of Two ${ }^{238}$ Pu Power Sources," Nucl. App. Tech., Vol. 7, p. 62, 1969.

3. Marion, J. B., and Fowler, J. L., Fast Neutron Physics, Vol. 1, p. 61, Interscience Pub. Co., a division of John Wiley Book Co., N.Y., 1960.

4. Plutonium-238 Isotropic Fuel from Data Sheet, compiled by S. G. Abrahamson, AEC Research and Development Report MLM-1564, p. 5, Mound Laboratory, Miamisburg, Ohio.

5. Keepin, G. R., Physics of Nuclear Kinetics, Addison-Wesley Pub. Co., Inc., Reading, Mass., 1964.

6. Matlack, G. M., and Metz, C. F., Radiation Characteristics of Plutonium 238, Report 3696, Los Alamos Scientific Laboratory, Los Alamos, N. Mex., 1967.

7. Miller, C. G., and Truscello, V. C., "Compatibility Considerations Between Radiation Thermoelectric Generators and Scientific Experiments on Spacecraft, Interoffice Engineering Memo EM 701-41, Jet Propulsion Laboratory, Pasadena, Calif., 1969.

8. Keshishian, V., Shielding and Criticability of $\mathrm{Po}^{210}, \mathrm{Pu}^{2 s 8}$, and $\mathrm{Cm}^{244}$, TI-609023-001, Atomics International Div. of North American Rockwell, Canoga Park, Calif., 1968.

9. Stoddard, D. H., and Albensius, E. L., Radiation Properties of Pu $\mathbf{u}^{2 s}$ Produced for Isotopic Power Generators, DP 984, Savannah River Laboratory, Aiken, S.C., July 1965.

10. Lamarsh, J. R., Nuclear Reactor Theory, p. 557, Addison-Wesley Pub. Co., Reading, Mass., 1966.

11. Roberts, J. H., Neutron Yields for Several Light Elements Bombarded with Polonium a Particles, MDDC-731, Atomic Energy Commission, Germantown, Md., Jan. 7, 1947.

12. Evans, R. D., The Atomic Nucleus, McGraw-Hill Book.Co., N.Y., 1955.

13. Gingo, P. J., unpublished report.

14. Gorshkov, V. A., et al., "Neutron Yield from the Reaction $(\alpha, n)$ in Be, B , C, O, $\mathrm{F}, \mathrm{Mg}, \mathrm{Al}, \mathrm{Si}$, and Granite Irradiated with Polonium $\alpha$-Particles," Sov. J. Atomic Energy, Vol. 13, July 1962.

15. Breen, R. J., Hertz, M. R., and Wright, D. V., The Spectrum of PoloniumBeryllium Neutron Sources, Report MLN 1054(54), Mound Laboratory, Miamisburg, Ohio, July 13, 1955.

16. Arnold, E. D., "Neutron Sources," in IAEA Engineering Compendium on Radiation Shielding, Springer-Verlag, Vienna, 1968.

17. Bonner, T. W., Kraus, A. A., Jr., Marion, J. B., and Schiffer, J. P., "Neutrons and Gamma Rays from the Alpha Bombardment of $\mathrm{Be}^{9}, \mathrm{~B}^{11}, \mathrm{C}^{13}$, and $\mathrm{O}^{18}$," Phys. Rev., Vol. 102, No. 5, p. 1348, 1956. 


\section{References (contd)}

18. Taherzadeh, M., "Neutron Yield from the $(\alpha, n)$ Reaction in the Isotope $\mathrm{O}^{18}$," Nucl. Sci. Eng., Vol. 44, No. 2, May 1971.

19. Taherzadeh, M., and Dore, M. A., "Neutron Radiation Characteristics of Plutonium Dioxide Fuel," Interoffice Engineering Memo EM 342-141, Jet Propulsion Laboratory, Pasadena, Calif.

20. Tsenter, E. M., Khabakhpashev, A. G., and Perkin, I. A., "Gamma Ray from a Po-O ${ }^{18}$ Neutron Source," Sov. Phys., Vol. 37, No. 10, p. 806, 1960.

21. Harold, T. R., "Neutron Spectrum of $\mathrm{PuO}_{2}$ " Nucl. Appl., Vol. 4, p. 19, Jan. 1968.

22. Jordan, T. M., Beta-A Monte Carlo Computer Program for Bremsstrahlung and Electron Transport Analysis, TR 68-111, Air Force Weapons Laboratory, Oct. 1968.

23. Bair, J. K., and Willard, H. B., "Level Structure in $\mathrm{Ne}^{22}$ and $\mathrm{Si}^{30}$ from the Reaction ${ }^{18} \mathrm{O}(\alpha, n){ }^{21} \mathrm{Ne}$ and $\mathrm{Mg}^{26}(\alpha, n) \mathrm{Si}^{24}$," Phys. Rev., Vol. 128, p. 299, 1962.

24. Bubernak, J., Matlack, G. M., and Metz, C. F., "Neutron and Gamma Radiation from ${ }^{238} \mathrm{Pu}$," LASL Trans. Am. Nucl. Soc., Section 11, p. 457, 1968.

25. Boling, M. A., and Rhoades, W. A., NAA Program Description, ANSIN/DIF II, AI-66-Memo 171, Vol. 1, Atomics International Div. of North American Rockwell Corp., Canoga Park, Calif., 1967. 
$N 72-26528$

TECHNICAL REPORT STANDARD TITLE PÁ́GE

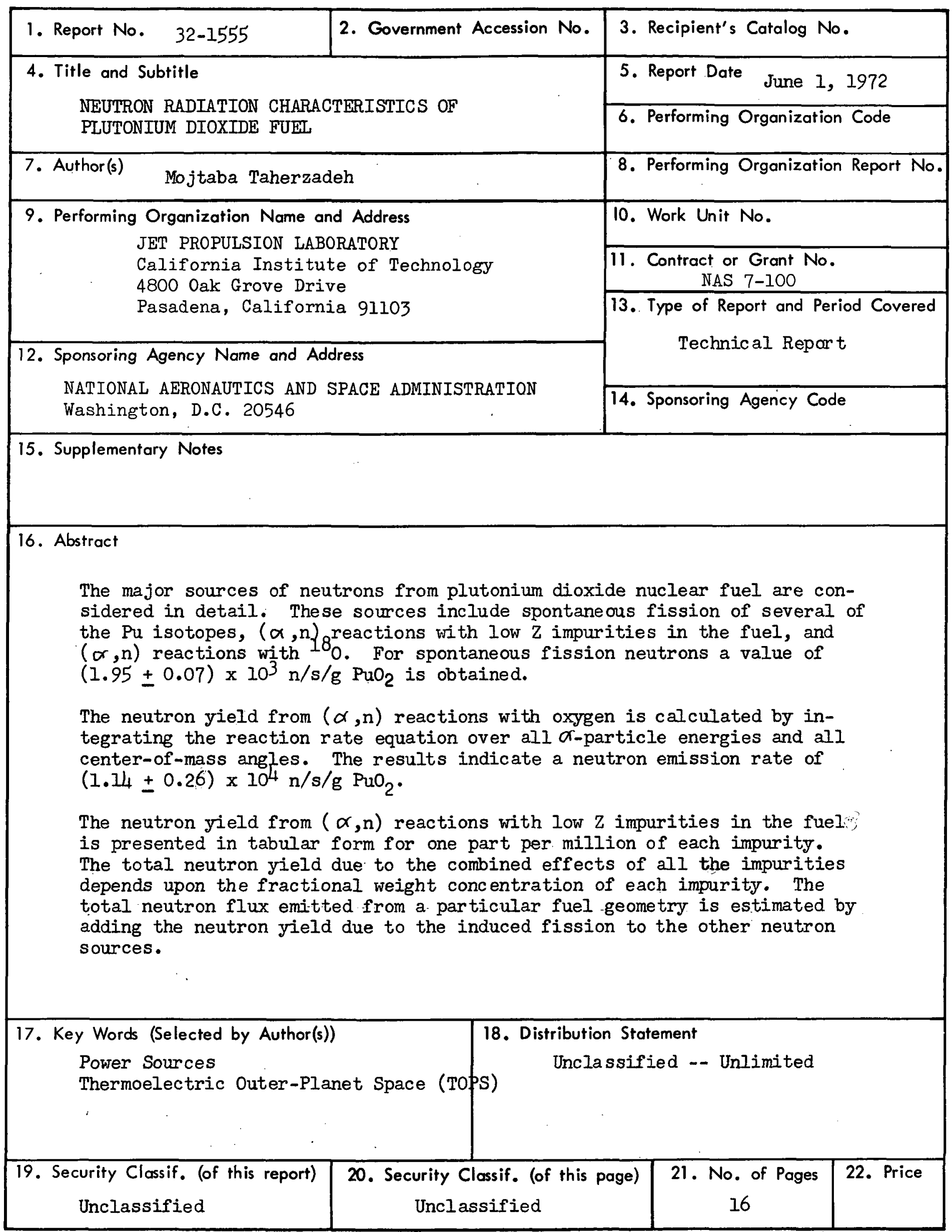


HOW TO FILL OUT THE TECHNICAL REPORT STANDARD TITLE PAGE

Make items 1, 4, 5, 9, 12, and 13 agree with the corresponding information on the report cover. Use all capital letters for title (item 4). Leave items 2, 6, and 14 blank. Complete the remaining items as follows:

3. Recipient's Catalog No. Reserved for use by report recipients.

7. Author(s). Include corresponding information from the report cover. In addition, list the affiliation of an author if it differs from that of the performing organization.

8. Performing Organization Report No. Insert if performing organization wishes to assign this number.

10. Work Unit No. Use the agency-wide code (for example, 923-50-10-06-72), which uniquely identifies the work unit under which the work was authorized. Non-NASA performing organizations will leave this blank.

11. Insert the number of the contract or grant under which the report was prepared.

15. Supplementary Notes. Enter information not included elsewhere but useful, such as: Prepared in cooperation with... Translation of (or by)... Presented at conference of... To be published in...

16. Abstract. Include a brief (not to exceed 200 words) factual summary of the - most significant information contained in the report. If possible, the abstract of a classified report should be unclassified. If the report contains a significant bibliography or literature survey, mention it here.

17. Key Words. Insert terms or short phrases selected by the author that identify the principal subjects covered in the report, and that are sufficiently specific and precise to be used for cataloging.

18. Distribution Statement. Enter one of the authorized statements used to denote releasability to the public or a limitation on dissemination for reasons other than security of defense information. Authorized statements are "Unclassified-Unlimited; "U.S. Government and Contractors only," "U.S. Government Agencies only," and "NASTA and NASA Contractors only."

19. Security Classification (of report). NOTE: Reports carrying a security classification will require additional markings giving security and down'grading information as specified by the Security Requirements 'Checklist' and the DoD Industrial Security Manual (DoD 5220.22-M).

20. Security Classification (of this page). NOTE: Because this page may be used in preparing announcements, bibliographies, and data banks, it should be unclassified if possible. If a classification is required, indicate separately the classification of the title and the abstract by following these items with either "(U)" for unclassified, or "(C)" or "(S)" as applicable for classified items.

21. No. of Pages. Insert the number of pages.

22. Price. Insert the price set by the Clearinghouse for Federal Scientific and Technical Information or the Government Printing Office, if known. 